Segmentation and Time-of-Day Patterns in Foreign Exchange Markets

Angelo Ranaldo

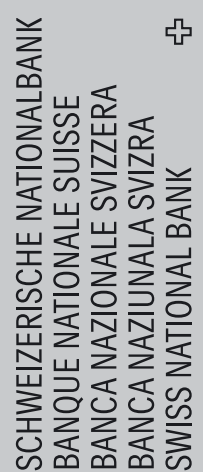

U 
The views expressed in this paper are those of the author(s) and do not necessarily represent those of the Swiss National Bank. Working Papers describe research in progress. Their aim is to elicit comments and to further debate.

ISSN $1660-7716$

๑ 2007 by Swiss National Bank, Börsenstrasse 15, P.0. Box, CH-8022 Zurich 


\title{
Segmentation and Time-of-Day Patterns in Foreign Exchange Markets*
}

\author{
Angelo Ranaldo ${ }^{\dagger}$ \\ Swiss National Bank
}

December 21, 2006

${ }^{*}$ The views expressed herein are those of the author and not necessarily those of the Swiss National Bank, which does not accept any responsibility for the contents and opinions expressed in this paper. I am very grateful to Adrian Trapletti for his insightful suggestions and generous support. The author also thanks Katrin Assenmacher, Dagfinn Rime, Paul Söderlind and an anonymous referee for their comments. All errors remain mine.

${ }^{\dagger}$ Angelo Ranaldo, Swiss National Bank, Research, Börsenstrasse 15, P.O. Box 2800, Zurich, Switzerland. E-mail: angelo.ranaldo@snb.ch, Phone: ++41.44.6313826, Fax: ++41.44 .6313901 . 


\title{
Segmentation and Time-of-Day Patterns in Foreign Exchange Markets
}

\begin{abstract}
This paper sheds light on a puzzling pattern in foreign exchange markets: Domestic currencies appreciate (depreciate) systematically during foreign (domestic) working hours. These time-of-day patterns are statistically and economically highly significant. They pervasively persist across many years, even after accounting for calendar effects. This phenomenon is difficult to reconcile with the random walk and market efficiency hypothesis. Microstructural and behavioural explanations suggest that the main raison d'être is a domesticcurrency bias coupled with market segmentation. The prevalence of domestic (foreign) traders demanding the counterpart currency during domestic (foreign) working hours implies a cyclical net positive (negative) imbalance in dealers' inventory. In aggregate, this turns into sell-price (buy-price) pressure on the domestic currency during domestic (foreign) working hours.
\end{abstract}

Keywords: foreign exchange market; microstructure; behavioural finance; timeof-day patterns; market segmentation; calendar effects; inventory; asymmetric information; high-frequency data.

JEL Classifications: F31; G10; G14; G15. 


\section{Introduction}

This paper provides striking evidence on spot exchange rates: Home currencies depreciate systematically during domestic working hours and appreciate during the working hours of the foreign counterpart country. Our database covers more than a decade's worth of data stored in a high-frequency database, with several currency pairs that, taken together, cover more than $52 \%$ of total market turnover by currency pair in 2004 (BIS (2005)). A clear picture emerges: first, this pervasive time-of-day pattern is highly significant, both statistically and economically; second, it spans many years and overrides calendar effects.

The fact that exchange rates follow cyclical patterns during the day challenges the random walk and efficient market hypothesis. An efficient market is one where the market price is an unbiased estimate of the true asset value. Deviations between true and market prices should be random, not systematic and cyclical. Given its characteristics, the foreign exchange market is the foremost aspirant to market efficiency. It is the world's largest financial market $^{1}$, with low transaction costs, and is widely backed by derivative instruments. It is a real global market open 24 hours a day. In it, various atomistic and price-taking market participants trade identical assets virtually, from many locations, and they can react almost instantaneously to news items. Operationally, trades are triggered on several competing microstructures and exchange systems, such as through dealers, brokers, ECNs, phone networks and nonbank internet sites. ${ }^{2}$ Why do so many rational and utility-maximising investors systematically incur recurrent higher transaction costs in such a competitive environment? Why do they not arbitrage this market anomaly?

After having documented the statistical and economic significance of this phenomenon, we attempt to explain why it exists. On the basis of a simple microstructural framework, we identify the main factors that help to determine these patterns. Two main explanations emerge: inventory and asymmetric information effects. The former refers to imbalances in the inventories of liquidity suppliers that are caused by systematic excess demand or supply at specific intraday times. The latter refers to the possibility that traders may profit from superior information because of their networking, trading location and the time zone in which they operate. We argue that the former factor is more important. In particular, this main explanation is derived from a combination of two factors: first, the prevalence of domestic currencies in the portfolio allo-

\footnotetext{
${ }^{1}$ The average daily turnover on the foreign exchange market amounted to $\$ 1.9$ trillion in April 2001 (BIS, 2005), more than 5 times the yearly turnover of all equities traded at NYSE.

${ }^{2}$ E.g. Deal4Free of CMC established in 1996; IFX Markets (since 1999); MatchbookFX (started in 1999 and closed down in 2000); HotSpotFX (since 2001) and Oanda (since 2001).
} 
cations of domestic investors and second, market segmentation. With respect to these two factors, we will henceforth refer to 'domestic-currency bias' and 'domestic-time bias'. The domestic-currency bias means that traders located in one specific country tend to hold assets denominated in the reference currency of that country. Their portfolios typically include domestic assets and, therefore, the domestic currency prevails over foreign currencies. This idea parallels the international home-bias literature (see Lewis (1999) for a survey). The domestic-time bias refers to the actual time when trading is done. Evidence on the imperfect integration of foreign exchange markets is provided by Hsieh and Kleidon (1996). As in the case of the proximity bias for equity markets (e.g. Massa and Simonov (2006)), we argue that investors have a tendency to trade mainly in their country's working hours. For instance, US investors, brokers and dealers will tend to exchange US dollars against euros during the main US hours of work. Conversely, the execution of euro-dollar spot exchanges initiated by European investors is clustered within the main working hours of central Europe. In a trading environment with an imperfectly elastic supply, the combination of these two factors gives rise to a cyclical pattern: the home currency depreciates during domestic working hours and appreciates during foreign working hours. In aggregate, the geographic segmentation, coupled with the domestic-currency bias, creates sell-price (buy-price) pressure during domestic (counterpart) working hours.

In order to obtain empirical support for these arguments, we use two methods to examine currency movements. First, we perform a time-series analysis of intraday currency returns to examine linkages across time and world regions. The prevalence of reversal rather than persistent patterns in currency returns suggests that the inventory hypothesis is more plausible. Second, a natural experiment is to test what happens when one of the two counterpart countries or regions is on holiday. If the foreign country is on holiday while people in the home country are working, it seems likely that during domestic working hours the domestic sell-pressure on the domestic currency will be exacerbated by the diminished buy-pressure from foreign investors. On the other hand, during foreign working hours, foreign investors will be relatively inactive and will not exert the usual buy-pressure on the domestic currency. This will result in stronger depreciation of the home currency during domestic working hours and weaker appreciation during foreign working hours. Our empirical findings largely support this supposition.

Surprisingly, the literature to date has almost nothing to say about the intraday patterns of exchange rate returns. Most of the attention in previous 
studies has been devoted to intraday volatility or bid-ask spreads, rather than returns. The Olsen \& Associates study was a real pioneer in collecting and analysing high-frequency data (e.g. Dacorogna et al. (1993), Olsen et al. (1997), and Müller et al. (1990)). However, its focus was on return volatility, bidask spread size and intensity of market activity, especially for foreign exchange markets. This is also the case for many other studies that have made significant contributions to the literature (Andersen and Bollerslev (1997, 1998), Baillie and Bollerslev (1990), Bollerslev and Domowitz (1993), Hsieh and Kleidon (1996), and Ito and Hashimoto (2005), just to mention a few). Ito (1987) and Ito and Roley $(1987,1991)$ represent an exception. However, they use only five points of time to analyse the intraday return behaviour of yen-dollar exchange rate from 1980 to 1986 . Our study adds to this literature by examining in finer detail the cross-sectional and time-series characteristics of intraday returns across different time zones, working time periods and calendar events.

This paper is structured as follows. Section 1 provides statistical evidence on time-of-day market patterns. Section 2 covers their economic significance. Section 3 presents a simple microstructure framework for studying the main drivers of this phenomenon. Section 4 presents some empirical findings supporting our hypotheses. Section 5 concludes the paper.

\section{Time-of-day patterns}

\subsection{Data}

The database has been kindly provided by Swiss-Systematic Asset Management SA, Zurich. It includes spot exchange rates for the following currency pairs: CHF/USD, DEM/USD, EUR/USD, JPY/EUR and JPY/USD. The sample periods cover the period from the beginning of January 1993 to the end of August 2005 for the CHF/USD and JPY/USD exchange rates, and from January 1999 to August 2005 for EUR/USD and JPY/EUR. Data for DEM/USD cover the period from January 1993 to December 1998. The introduction of the euro dictates the time periods for the euro and the German mark. We use the tick-by-tick FXFX Reuters midquote price (the average price between the representative ask and bid quotes). The characteristics of these data have been discussed at length in previous studies (among others, Müller et al. (1990), Dacorogna et al. (1993) and Goodhart, Ito and Payne (1996)). Although indicative quotes have their shortcomings, a comparison of the electronic foreign exchange trading system, Reuters 2000-2, with FXFX Reuters shows that "FXFX indicative quotes can be taken as a very good and close proxy for that in the Reuters 
2000-2" (Goodhart, Ito and Payne (1996), page 126). ${ }^{3}$

The dataset contains millions of representative quotes. To conduct this study, we carefully organised our database as follows: first, we accounted for changes in daylight savings times, expressing time in terms of Greenwich Mean Time (GMT). Second, we organised our database in 5-minute intervals. For each interval, we identified the first, last, high and low exchange rates. If no trades occurred in a given 5-minute interval, we copied down the last trading price in the previous time interval. Finally, since our database included weekends, we excluded weekend hours according to the definitions reported in Table 1 . The definition of weekend hours matches the beginning and end of working hours in the different time zones. Thus, for each currency pair, the working week begins at 6 a.m. in the earliest time zone and ends at 6 p.m. in the latest time zone, expressed in terms of Greenwich Mean Time. For instance, for JPY/USD, the working week begins when it is 6 a.m. on Monday in Tokyo (corresponding to 9 p.m. on Sunday, GMT) and ends at 6 p.m. on Friday in New York local time (11 p.m. on Friday, GMT). It is worth stressing that the inclusion of weekends leaves the main results unchanged. But it has the disadvantage of blurring some of the intraday effects.

For the sake of presentation, we investigate exchange rate movements over 4-hour periods. These time brackets allow us to observe overlapping and nonoverlapping intraday periods in the different working hours of each world region. In particular, trading hours from midnight to 4 a.m., from 8 a.m. to midday and from $4-8$ p.m. GMT mirror the main trading activity in Japan, Europe and the US, respectively. A 4-hour time interval is also a reasonable length of time for marketable intraday trading. In principle, one could question whether shorter timeframes than four hours provide a finer identification of short-lived patterns. But it turns out that shorter timeframes deliver a nosier picture of the same phenomenon. The descriptive analysis over one-hour time intervals is available upon request.

\section{$2.2 \quad$ Statistical significance}

Figure 1 presents time-of-day return patterns in graphical form. Each graph shows 24 cross-sectional averages of annualised returns over four hours. Using two-sample t-tests, these graphs also show if the acceptance of the null hypoth-

\footnotetext{
${ }^{3}$ Martens and Kofman (1998) show that futures on DM/\$ tend to lead the "quoted" spot market for up to 3 minutes. This lead-lag relation does not constitute critical evidence for our study. Lyons (1995) stresses three limitations related to "indicative" quotes: they are not tradable; they are representative only for the interbank market; during very fast markets, "indicative" quotes may be updated with a short delay.
} 
esis of equality in means falls below the p-value of $5 \%$ or $1 \%$. In figure 1 , black (grey) bars mean that an average return over a specific 4-hour time period is different at a $1 \%(5 \%)$ significance level. ${ }^{4}$ These figures clearly show that all currencies tend to depreciate during the working hours of their reference countries and to appreciate during the working hours of their counterpart countries. More specifically, these figures show:

- CHF/USD: the US dollar appreciates significantly from 5:00 to 13:00 GMT and the Swiss franc appreciates significantly from midday to 17:00 and then again from 17:00 to 23:00 GMT.

- DEM/USD: similar to CHF/USD, the US dollar appreciates significantly from 5:00 to 13:00 GMT and the German mark appreciates significantly from midday to 17:00 GMT.

- EUR/USD: the US dollar appreciates significantly from 8:00 to 12:00 GMT and the euro appreciates significantly from 16:00 to 22:00 GMT.

- JPY/EUR: the euro appreciates significantly from 1:00 to 6:00 GMT and the yen appreciates significantly from 8:00 to 15:00 GMT.

- JPY/USD: the US dollar appreciates significantly during the night (from 22:00 to 4:00 GMT) and the yen appreciates significantly from 12:00 to 16:00 GMT.

The trading influence from world regions other than the two counterparties is weaker, but still visible. In particular, trading in Japanese trading hours appears to support the US dollar against the euro (see figure $1 \mathrm{C}$, during the night from 21:00 to 2:00 GMT), US trading supports the euro against the yen (figure 1D, 14:00-22:00 GMT) and during European hours the dollar depreciates against the yen (figure 1E, 5:00-11:00 GMT).

The dollar depreciation (appreciation) against the yen during US (Japanese) business hours is the weakest pattern we have found (although it is still significant). Our results apparently contrast with those obtained by Ito and Roley (1987), who found opposing patterns from 1980 to 1986. There are several explanations for this apparent anomaly. First, Ito and Roley use a more rigid and rough definition of intraday periods. Having only five data points in time, they define - for instance - the opening time for the US market as 9 a.m. Eastern

\footnotetext{
${ }^{4}$ These t-statistics refer to two-tail statistics on the difference between a given 4-hour return mean over all the other 4 -hour returns. Note that we perform the two-sample equal variance (homoscedastic) test. This represents a more severe test than the heteroscedastic hypothesis. In fact, the probability associated with a Student's t-test for equality in means has an upward bias and leads to a more likely rejection of the inequality hypothesis.
} 
Time, despite the fact that at that time the derivatives markets in Chicago are already open, and after the announcement of major pre-scheduled news bulletins such as those on GDP, the unemployment rate and the balance of trade. Second, as pointed out by Ito and Roley (1987), the yen-dollar exchange rates from 1980 to 1986 are characterised by the "over-valued" dollar policy and strong temporary trends. Froot (1991) also shows that Japanese outflows of foreign direct investment increased dramatically in the eighties, and half of the Japanese capital outflow was directed towards US.

Table 2 shows more detailed descriptive statistics. Here, six non-overlapping 4-hour time intervals represent the entire trading day. Means, medians and standard deviations are reported on an annualised basis ${ }^{5}$ to ease reading. Tests for inequality in means and medians (Wilcoxon/Mann-Whitney test) corroborate the previous results. In line with the previous literature, intraday heteroskedasticity is clearly observable (F-tests show statistical significance). The max and min and the statistics on the third and fourth moments suggest that distributions are reasonably centred, acceptably well-shaped with respect to a Gaussian distribution and moderately affected by outliers. ${ }^{6}$ It is also interesting to note that 4-hour returns outside the main working hours are not serially correlated across consecutive days. ${ }^{7}$ For instance, for CHF/USD there is an autoregressive pattern during Swiss and US working hours only. This is another indication that clock-time influences trading-time.

There are some institutional aspects that can represent a preliminary explanation for the time-of-day patters. First, it is worth noting that there is a specific point in time that can be considered to be the end of the trading day on spot foreign exchange markets. This is 21:00 GMT, the time when the New York market closes. An open spot position after 21:00 GMT implies the payment of an interest rate differential between the long currency and the short currency over the next working day. Our results show that this point in time has no particular effect on intraday returns. Only in the case of euro-dollar exchange rates we do observe significant movement. Second, as discussed by Lyons

\footnotetext{
${ }^{5}$ To annualise, 4-hour returns are multiplied by 260 .

${ }^{6}$ We checked the correspondence between our intraday outliers, using Datastream daily data. There is consistent matching. In particular, the max and min 4-hour returns for JPY/USD are concentrated around 8 October 1998. On that day, this exchange rate experienced marked fluctuations. The dollar depreciated strongly around 10:00-12:00 GMT and recovered around 15:00-18:00 GMT. Datastream data indicate that the daily (log) changes on 7 and 9 October 1998 amounted to $-7.7 \%$ and $-2.3 \%$, respectively. (The original source of these data is the Global Treasury Information Services, which fix the closing quote at 13:00 GMT).

${ }^{7}$ See "Q-stat 1 " in table 2, showing the Q-statistic for testing the null hypothesis that there is no autocorrelation at lag 1, i.e. serial correlation between one day's intraday return occurring in a given 4-hour period and the previous day's intraday return occurring at the same time of the day.
} 
(1995), many banks impose overnight limits on their dealers' positions. Moreover, most dealers close their day with a zero net position and then they restore their inventory in the early morning of the trading day to face the oncoming liquidity demand (Lyons (1998)). Thus, intraday and overnight trading limits may determine time-of-day patterns. Finally, the common practice in foreign exchange markets is to hedge only partially the aggregate dealer's position. On the other hand, dealers tend to adjust unbalanced inventory levels on a single currency pair over (short) intraday periods. Lyons (1995) shows that FX dealers prefer to reduce inventory over given thresholds via outgoing orders or brokered trades. This practice implies a transmission mechanism of transient inventory imbalances among dealers. Overall, this reasoning provides us a prima facie explanation for temporary trends in exchange rates due to inventory problems.

\subsection{Calendar effects}

We examine how intraday returns are distributed across time and whether our results may be affected by particular calendar effects. In particular, we check whether these intraday seasonalities cluster at given points of time. There is no specific month in the year responsible for this phenomenon (not displayed). Hence, the year-change or January effect that characterises equity markets does not appear to hold for currencies. Figure 2 shows that the time-of-day anomaly is evenly distributed across the years. By taking the US investor (European investor for JPY/EUR) point of view, figure 2A plots domestic currency appreciation during foreign working hours, year by year, from 1993 to 2005. Figure $2 \mathrm{~B}$ shows domestic currency depreciation during domestic working hours. Only in a very few cases do we observe exceptions to the general pattern; in particular, the US dollar appreciated noticeably against the Swiss franc during US working hours in 1999 and 2005. However, it is evident that the time-of-day phenomenon persists over years.

Table 3 reports how the time-of-day patterns are spread across weekdays. For simplicity, we annualise returns. Some interesting results emerge. As far as the US dollar is concerned, the time-of-day anomaly exerts the strongest effect during US working time on Thursdays. In general, the US dollar depreciates 5\%-7\% against European currencies during US working hours, and $4 \%$ against the yen. On Thursdays, the dollar experiences an additional depreciation of $2 \%-$ 4\%. European currencies, including the Swiss currency, appear more affected by trading activity on Mondays and Wednesdays. Indeed, the euro, German mark and Swiss franc have a tendency to loose $3 \%$ or more than the usual morning depreciation on Mondays (8:00-12:00 GMT). The additional appreciation of the 
euro during this intraday period increases from $7.8 \%$ to $15.7 \%$ against the yen. In turn, the yen seems to be more exposed to an end-of-the-week effect. On Friday morning (local time), the yen looses $13.6 \%$ on average against the dollar and $10.5 \%$ on average against the euro, as compared to the normal $2.7 \%$ and $2.9 \%$, respectively. There are two main arguments that could help to explain these deterministic patterns. On the one hand, the non-trading hours over the weekend may strengthen time-of-day effects on Mondays and Fridays. The weekend effect on equity markets has been extensively documented (e.g. French (1980)). A similar effect may exist on currency markets. On the other hand, the literature shows that major public information announcements, such as macroeconomic news, have a significant effect on foreign exchange rates (cf. among others, Andersen et al. (2003), Andersen and Bollerslev (1998), Bauwens, Ben Omrane and Giot (2005), Ederington and Lee (1993), Evans and Lyons (2005)). Since these news announcements are pre-scheduled and released recurrently on the same day of the week, the day-of-the-week effect discussed above may be related to information releases. Finally, an additional issue that may influence intraday price movements is the occurrence of central bank interventions. However, these are typically conducted on an irregular and occasional basis. Moreover, the literature shows that intervention operations are controversial policy options and may lead to mixed results (e.g. Dominguez (1998)). So, it is hard to believe that deterministic patterns such those in table 3 can be explained by irregular events such as central bank interventions.

\section{Economic significance}

While this time-of-day phenomenon appears highly significant in statistical terms, a further natural question would be whether it is also significant in economic terms. We attempt to answer this question by applying some simple trading rules. Five main rules are investigated. Their performance is summarised in Table 4. The first (second) rule consists in taking a long (short) position each working day for four of the foreign (domestic) working hours. The long position on US dollars is from 8:00 to noon if the counterpart currency is the Swiss franc, German mark or euro, and from midnight to 4:00 as far as the yen is concerned. The short position on the dollar spans the hours from midday to 16:00 if the counterpart currency is the Swiss franc, German mark or Japanese yen, and from 16:00 to 20:00 for the euro. The short positon on euro

against yen occurs from 8:00 to noon. The third strategy combines the first two rules, i.e. a long-short strategy each day. Since we have observed some day-of- 
the-week effects, the fourth and fifth strategies focus only on one specific trading day in the week. The fourth trading rule implements a short-long strategy on Mondays only. This should have a particularly positive effect on performance during European working times. The final trading rule executes a short-long strategy with respect to the Japanese yen on Thursdays or Fridays only. These specific days are consistent with the day-of-the-week effects reported in Table 3. Taking annualised values, performance is evaluated in terms of mean return, standard deviation and Sharpe ratio. We also implement a simple time-series analysis by estimating the market model as follows:

$$
r_{t}^{S}=\alpha+\beta r_{t}^{D}+\epsilon_{t}
$$

The dependent variable $r_{t}^{S}$ is the intraday return on day $t$ resulting from the strategy $S$ that could be one of the five trading rules explained above. The return on the benchmark asset $r_{t}^{D}$ is represented by the daily (log) change on the currency pair. The day is defined as lasting from 0:00 to 24:00 GMT. Other definitions provide essentially the same results. The market model estimation gives the size of alpha (annualised) and beta that can be interpreted in the traditional sense, namely the risk-adjusted Jensen measure and the beta coefficient as a measure of systematic risk.

It is worth emphasising that the implementation of these rules does not aim at maximising profitability. In fact, to be consistent with the rest of the paper, these rules are applied to the six four-hour periods mentioned above and not to the intraday periods affording the maximum average returns. For instance, the long position on Japanese yen taken by a European investor trading on JPY/EUR has been set for the midnight-4:00 time intervals (GMT) that provide a return of only $2.8 \%$. This position would earn $7.6 \%$ if carried out from 17:0022:00. Furthermore, more sophisticated operations such as the use of leverage or (intraday) timing are simply ignored. ${ }^{8}$

Table 4 shows that even the minimal long and short rules provide significant results in economic terms. The combined long and short strategy increases performance twofold. Long-short strategy performance ranges from 6.7\% (JPY/USD) to $16.7 \%$ (EUR/USD). These numbers translate into 0.96 and 2.41 in terms of Sharpe ratios. The implementation of day-of-the-week strategies magnifies these yields further. The long-short strategy on Mondays and Thursdays attains almost $20 \%$ of annual returns, with a Sharpe ratio of more than 3.5 .

The market model estimation for equation (1) yields the following results.

\footnotetext{
${ }^{8}$ For a theoretical underpinning to optimise the trading timing, see Shirayev (1978).
} 
First, alphas are exactly in line with the mean returns reported above. Second, beta estimates suggest a fairly low exposure to systematic risk. Betas (in absolute values) for long and short trading rules (taken separately) are around 0.2-0.3. These values decrease when long and short strategies are combined. Betas for weekday strategies are slightly higher than the pure long-short rule which essentially involves a negligible systematic risk and a solely positive alpha.

The consideration of transaction costs significantly worsens some of the strategy performances above. We calculate the break-even cost for each currency strategy. This means that we estimate the implicit maximum cost necessary to avoid incurring losses. To do this, we charge the largest quoted bid-ask spreads ${ }^{9}$ or the round-trip cost, each time a long or short strategy is adopted, and twice the round-trip cost for the long-short strategies. The first three trading rules involve a great deal of trading because they imply that a transaction is carried out each working day. For this reason revenues are significantly reduced by transaction costs in these cases. However, it appears that the EUR/USD pair, at least, provides lucrative speculation, even after adjusting for transaction costs. In these cases, time-of-day currency strategies can bear transaction costs as high as 4 pips $^{10}$ before moving into a negative range. This magnitude of spread is large when compared with the typical interdealer bid-ask spreads documented in the previous literature. ${ }^{11}$

To complement this analysis, Table 4 also shows the average representative bid-ask spreads encountered in our data. We took into consideration the average bid-ask spread size surrounding the beginning and end time of the intraday holding periods (e.g. nearby 8 a.m. and noon for the 8:00-12:00 long strategy). It is worth noting that average spreads from the Reuters representative quotes are larger than interdealer spreads and tend to overestimate transaction costs. Table 4 shows that the payoff increases significantly if we consider day-of-the-week strategies. In fact, these strategies are much less costly and more remunerative. In most cases, break-even costs are between 10 and 19 pips. These numbers appear highly profitable even when compared with the representative bid-ask spreads.

\footnotetext{
${ }^{9}$ It is worth noting that intraday cost-of-carry is virtually zero in spot currency markets. Provided with cash holdings to invest, a spot trading position opened after 21:00 GMT of the previous day and closed before 21:00 GMT of the current day pays no interest rates.

${ }^{10}$ One pip for currency pairs involving the Japanese yen corresponds to 0.01 . One pip is the fourth decimal for the other currencies, i.e. 0.0001.

${ }^{11}$ Here, we mention only few studies reporting indications about the spread size. Ito and Hashimoto (2005) report an average spread size between 0.015 and 0.025 for JPY/USD and 0.0001 and 0.0002 for EUR/USD in the EBS system during 1999-2001. According to Lyons (2001), the median spread for DEM/USD was already low in 1992, i.e. around 3 pips. Goodhart et al. (2002) find that the average spread in both DEM/USD and USD/EUR was between 2 and 3 pips using data from 1997 to 1999.
} 


\section{A theoretical framework}

In this section, we present a simple theoretical framework designed to identify the main aspects that may influence trader behaviour and ultimately determine the time-of-day patterns. We closely follow the Biais, Glosten and Spatt (2005) model, since this has the advantage of covering the main characteristics of traders' decisions in a unified theoretical framework. These include non-competitive pricing, order-handling, inventory and adverse selection costs. Although there is a new strand of literature in which the microstructure of foreign exchange markets is modelled - including advanced representations of the currency market microstructure (e.g. Evens and Lyons (2002a, 2002b) and Lyons (2001)) - these models typically focus on the dealer's behaviour while, in our setting, the distinction between liquidity supplier and demander as well as the final investor play an essential role. Here, risk-aversion, inventory risks and adverse selection characterise the decisions of both the (rational) liquidity provider and demander.

The model is explained in greater detail in the appendix. We consider a spot exchange rate for a currency pair to be a risky asset. The market is populated by $\mathrm{N}$ competitive liquidity suppliers and a representative liquidity demander. Both liquidity suppliers and demanders are assumed to have a Constant Absolute Risk Aversion (CARA) utility function and an initial currency endowment. The liquidity demander initiating the trade is the most active part, often called the initiator or aggressor. He can have liquidity or informational reasons to trade. In the former case, the primary source of currency demand is a final investor or customer. ${ }^{12}$ The sequence is as follows: a customer contacted his bank that acts as market maker; a dealer in the bank then turns to the interbank market to cover the customer trade. In this circumstance, the dealer mimics the customer behaviour. In the latter case, the dealer has informational motives to trade. Lyons (1995) calls for a boarder view of private information in the forex market. ${ }^{13}$ In particular, dealer's conjectures on aggregate inventories or on other dealers' expectations may motivate trading for reasons apart from portfolio re-allocation or liquidity needs. In both cases, the aggressor represents the liquidity demander and the nonaggressor is the liquidity supplier. ${ }^{14}$

\footnotetext{
12 These can be very diverse, e.g., central banks, governments, importers and exporters of goods, financial institutions, hedge funds and so on.

${ }^{13}$ See, also, Cao, Evans and Lyons (2006) for a discussion on the nature of (a)symmetric information in FX markets.

${ }^{14}$ If the two parts are both dealers ("direct trading"), the nonaggressor dealer may choose to provide liquidity as a market maker and give quotes on the aggressor dealer's request (so called "incoming trade"), or he may trade on other dealers' quotes ("outgoing trade"). Since the interbank market is a hybrid market, dealers can interact with brokers ("indirect trading") by giving quotes to them (via limit orders) or by trading at brokers' quotes (market orders).
} 
In our setting, the initial endowment in an investor's currency plays a pivotal role. It identifies the domestic-home bias. To model this, we extend the BiaisGlosten-Spatt model by assuming that the representative investor comes from a bivariate mixture of two groups, the domestic and foreign participant groups, with a normal distribution. Since each group favours its reference currency, the former (latter) representative agent will, on average, be positively (negatively) endowed with domestic currency.

To see how the initial endowment determines the price formation process, let us assume that there are three representative phases in trading activity. In one phase, domestic and foreign traders are essentially equally represented and there is no market pressure due to the domestic-currency bias. In terms of nonaggressor's expectations, this means $E\left[\omega_{D} L_{D}+\omega_{F} L_{F}\right]=0$ in the model terminology described in the appendix. The second phase occurs during domestic working hours. In aggregate, the prevalence of domestic investors on the market implies a positive imbalance in domestic currency and, in turn, an excess demand for foreign counterpart currency. This translates into a positive inventory imbalance for liquidity providers, who will typically react by overbidding ask quotes for the foreign-to-domestic exchange rates. ${ }^{15}$ From the dealer's eyes, this means $E\left[\omega_{D} L_{D}\right]>E\left[\omega_{F} L_{F}\right]$. Finally, the opposite mechanism holds if counterpart investors prevail in the market.

The liquidity demander is also endowed with an initial signal on the final asset value. Thus, the aggressor may also have informational motives to trade. To trade, an aggressor will place a market order by rationally anticipating the impact of his trading volume on the price. Once the market order has been submitted, equilibrium is achieved in a simple uniform-price auction, in which the liquidity supplier optimally designs his limit order schedule by choosing, for each possible price, a given quantity to supply. He does so by conjecturing the information signal and the risk-sharing needs from the submitted market order.

This simple model points to two main causes for the time-of-day patterns: first, liquidity demand and supply; second, information asymmetry. The first argument hinges on the intraday seasonalities of excess demand for or supply of currencies. Ceteris paribus, the investor with a positive initial endowment in domestic currency (positive $L$ ) is more willing to buy foreign currency. Since domestic traders assemble their orders during domestic working time $\left(\omega_{D}>\omega_{F}\right)$, liquidity providers face an aggregate positive inventory imbalance in the domestic currency during domestic working hours (larger $I$ ). Overall, this market

\footnotetext{
${ }^{15}$ More precisely, the dealer will react by overbidding quotes in case of "direct" quantity quotation (home currency as price currency) and by undercutting quotes in case of "indirect" quotation (home currency as unit currency).
} 
force translates into selling pressure on the domestic currency (negative trading volume $Q$ ), a higher price impact $(\lambda)$ and a decreasing price. At the same time, a higher volatility or dispersion in the initial endowment of the aggressors (variance of $L$ ) tends to decrease the price impact and augments trading volume.

Information asymmetry represents a second possible explanation. A stronger private signal with respect to the domestic currency value, $s$, translates into a higher demand (larger $Q$ ) and currency appreciation (higher $P$ ). On the other hand, the larger the number of liquidity traders participating in the market $(N)$, the lower the market impact, the higher the trading volume and the lower the price impact. In contrast, a rise in the liquidity trader's risk aversion $(\kappa)$ strengthens the price impact. Finally, higher variance in the private signal (true asset value) increases (decreases) the noise signal $(\delta)$ and price impact, and decreases (increases) trading volume.

Thus, we have two conflicting explanations: inventory and information asymmetry effects. These two explanations entail two opposite empirical implications, both of which can be tested. ${ }^{16}$ First, significantly positive cross-sectional depreciation (appreciation) of the domestic currency during domestic (foreign) working hours would point more strongly to an intraday seasonally-based excess demand for or supply of foreign currency. Consequently, the marked patterns described above and shown in figure 1A-E would tend to support the inventory hypothesis rather than the asymmetric information approach. In fact, it is implausible that domestic traders should systematically enjoy superior information on a negative (positive) signal during domestic (foreign) trading hours. In this respect, the asymmetric information hypothesis would imply insignificant crosssectional intraday return averages. Hsieh and Kleidon (1996) arrive at the same result by analysing volatility periodicities on foreign exchange markets. They conclude that these recurrent patterns are not due to the incorporation of private information, as envisioned by standard asymmetric information models, but rather to inventory-bearing risk inherent in the market-making mechanism. ${ }^{17}$

Second, information asymmetry implies permanent price adjustment, whereas the price impact due to inventory problems is typically reversed. In fact, the price impact attributable to inventory aspects is temporary since it is not driven by valuable information about true asset value. If asymmetric information were

\footnotetext{
${ }^{16}$ Lyons (1995) tests the inventory and information asymmetry hypotheses using different methods and data. He uses transaction data of one dealer and one broker in the U.S. market for five days during August 1992.

${ }^{17}$ Likewise, Breedon and Vitale (2005) find that the relationship between exchange rates and forex order flow is mostly due to liquidity effects rather than any information contained in order flow. Further empirical evidence on the relevance of inventory effects in currency markets may be found in Bessembinder (1994), Cao, Evans and Lyons (2006), Flood (1994), Lyons $(1995,1998)$.
} 
the sole motivation to trade, a sale at the bid would cause a permanent price fall to reflect private information conveyed by that sale. If inventory costs were the only dealer's concern, after a sale at the bid, bid and ask quotes would fall, not to reflect information as in the asymmetric information paradigm, but to discourage additional sales. Over time, however, quotes would return to normal. The same logic holds in case of a purchase. Consequently, reversal (continuation) in intraday price changes revealed by the time-series analysis would tend to support the inventory (asymmetric information) interpretation. ${ }^{18}$ The time-series analysis is presented below.

\section{$5 \quad$ Empirical findings}

Some trading aspects coming from the above theoretical framework are barely observable and testable, in particular the informed trader's private signal, true asset value volatility, risk aversion, number of liquidity suppliers, noise-to-signal ratio and so on. Consistently, our analysis focuses only on the main explanations that can be tested empirically, i.e. the inventory and asymmetric information effects.

\subsection{Time series analysis}

To contrast further the inventory and information asymmetry hypotheses, we conduct a time-series analysis by means of a Seemingly Unrelated Regression (SUR) model relating intraday price dynamics as follows:

$$
\mathbf{Y}_{t}=\mathbf{a}+\mathbf{b} \mathbf{X}_{t-1}+\mathbf{e}_{t}
$$

Where $\mathbf{Y}_{t}$ is a $6 x 1$ vector 4-hour consecutive return that, taken together, represents the log price over the previous 24 hours, specifically:

$$
\mathbf{Y}_{t}=\left[r_{t}^{20-24}, r_{t}^{16-20}, r_{t}^{12-16}, r_{t}^{8-12}, r_{t}^{4-8}, r_{t}^{0-4}\right]
$$

where, for instance, $r_{t}^{20-24}$ designates the return from midday to 4:00 GMT on day $t$. $\mathbf{a}$ and $\mathbf{b}$ are $6 x 1$ and $6 x 6$ matrices of parameters. $\mathbf{X}_{t-1}$ is a $6 x 6$ matrix containing the previous six 4-hour consecutive returns, as follows:

\footnotetext{
${ }^{18}$ This does not mean that return continuation is a necessary condition for observing trading motivated by specific information. In principle, it is possible that an investor with superior information will trade only once and that this will have a permanent impact. However, there are circumstances in which non-public information is processed into price more gradually, e.g. order splitting strategies, front-running trading, information leakages, news bulletins implying time-consuming analysis and so on.
} 


$$
\mathbf{X}_{t-1}=\left[\begin{array}{cccccc}
r_{t}^{16-20} & r_{t}^{12-16} & r_{t}^{8-12} & r_{t}^{4-8} & r_{t}^{0-4} & r_{t-1}^{20-24} \\
r_{t}^{12-16} & r_{t}^{8-12} & r_{t}^{4-8} & r_{t}^{0-4} & r_{t-1}^{20-24} & r_{t-1}^{16-20} \\
r_{t}^{8-12} & r_{t}^{4-8} & r_{t}^{0-4} & r_{t-1}^{20-24} & r_{t-1}^{16-20} & r_{t-1}^{12-16} \\
r_{t}^{4-8} & r_{t}^{0-4} & r_{t-1}^{20-24} & r_{t-1}^{16-20} & r_{t-1}^{12-16} & r_{t-1}^{8-12} \\
r_{t}^{0-4} & r_{t-1}^{20-24} & r_{t-1}^{16-20} & r_{t-1}^{12-16} & r_{t-1}^{8-12} & r_{t-1}^{4-8} \\
r_{t-1}^{20-24} & r_{t-1}^{16-20} & r_{t-1}^{12-16} & r_{t-1}^{8-12} & r_{t-1}^{4-8} & r_{t-1}^{0-4}
\end{array}\right]
$$

As we have seen above, autocorrelation in intraday returns does not last more than one day and only few 4-hour return periods are significantly related to price movements for the same intraday period of the previous day. Hence, the timeseries specification above allows us to assess continuation or reversal patterns through the intraday price discovery process, over an exhaustive period of time. However, this empirical test warrants some important caveats. In particular, it cannot capture inventory and asymmetric information effects over time periods shorter than four hours.

Three main patterns are discernable in Table 5. First, reversal patterns are visible over two time granularities: four hours before and one day before, for the same intraday time period. This suggests that inventory effects typically result in price setbacks over two consecutive intraday periods and during the same intraday period of the following day. ${ }^{19}$ Second, return persistence is less pervasive than price reversal but still observable. In particular, there is a significant positive autocorrelation between the two 4-hour periods constituting US working hours, i.e. 12:00-16:00 and 16:00-20:00 GMT. This continuation effect can be interpreted as a sign of an ongoing process of price adjustments or information asymmetry. $^{20}$ Finally, there are intraday periods which are more influential than others. In particular, what happens in the European morning (8:00-12:00 GMT) appears to be inversely related to late trading (20:00-24:00 GMT) in all currencies pairs apart from euro/dollar exchange rates. On the other hand, yen/dollar movements during Japanese hours (typically midnight to 4:00 GMT) are precursors of US trading activity (16:00-20:00 GMT). Also for the yen/dollar currency pair, price changes during US working hours (12:00-20:00 GMT) tend to be positively lagged during the European morning (8:00-12:00 GMT). These

\footnotetext{
${ }^{19}$ In his experimental design, Flood (1994) highlights the fact that, through the "hot-potato" mechanism, inventory imbalances can give rise to foreign market inefficiency. BIS (2005) shows that the "hot-patato" trade accounts for more than $50 \%$ of daily volume in 2004 . Sarno and Taylor (2001) stress that the decentralised nature of forex markets reduces currency market efficiency, especially in terms of price information, arbitrage opportunities, and order execution.

${ }^{20}$ Empirical evidence on adverse selection problems in foreign exchange markets may be found, inter alia, in Bjørnnes and Rime (2005), Marsh and O'Rourke (2005), Mende, Menkhoff and Osler (2006) and Payne (2003).
} 
lagged price adjustments can be partially explained by the lengthy time needed to absorb news (e.g. Evans and Lyons (2005)), the partial geographical integration of foreign exchange markets (e.g. Evans and Lyons (2002b) and Menkhoff and Schmeling (2006)) and the "meteor shower" hypothesis ${ }^{21}$ (Engle, Ito and Lin (1990)).

\subsection{Holiday effects}

Many aspects of trading behaviour are difficult to observe directly, in particular inventory holdings and information sets. Thus, the test for the determinants of the exchange rate formation process has to be conducted indirectly. We attempt this by comparing regular trading with the special market conditions that prevail when one of the two counterparts' activity is at a low level. The natural way to test this is to see what happens when one of the two counterpart countries or regions is on holiday. ${ }^{22}$ The list of holidays is included in Table 1. These data were kindly provided by the Swiss Banking Association, which keeps track of the official holidays for each country on an annual basis. We consider the case of non-overlapping national ${ }^{23}$ holidays, i.e. when there is a bank holiday in the foreign country while people in the home country are working as usual. For the European Union, we consider German holidays. We have tested other definitions of European holidays and the main results remain essentially unchanged. ${ }^{24}$ The lowest number of non-overlapping days is 36 (euro-dollar) and the highest is 100 (yen-dollar). This should represent a trading environment in which the market is relatively more (less) populated by domestic (foreign) traders. Using the terminology set out above, we might expect a predominance of market participants who are positively endowed with the domestic currency $(L)$ and a higher proportion of domestic agents $\left(\omega_{D}\right)$ together with a lower dispersion or heterogeneity of their endowment (variance of $L$ ). In turn, this market condition should strengthen liquidity traders' inventory risk. If this holds, we would observe stronger (weaker) domestic (foreign) pressure to sell (pressure to

\footnotetext{
${ }^{21}$ By meteorological analogy, Engle, Ito and Lin (1990) refer to a meteor shower for a situation in which volatility spreads across regions in chronological order ("it rains down on the earth as it turns") whereas the term heat wave refers to volatility transmission specific to one locality ("a hot day in New York is likely to be followed by another hot day in New York").

${ }^{22}$ Bessembinder (1994) analyses patterns in exchange rate volatility, trading volume and spreads before holidays. He finds that spreads do not increase by a significant margin before any single-country holiday but only before holidays in multiple financial centres.

${ }^{23} \mathrm{We}$ also tested the inclusion of holidays in some regions of a country, e.g. Corpus Christi in Germany. The results remain essentially unchanged. Therefore we decided to consider only national holidays.

${ }^{24}$ We analysed several combinations by including or excluding from German holidays official bank holidays in Belgium, France, Holland, Italy and Spain.
} 
buy) during domestic working hours. This imbalance would ultimately result in stronger depreciation of the home currency during domestic working hours and weaker appreciation during foreign working hours.

Table 6 reports the average and standard deviation of intraday returns on domestic and foreign holidays. These statistics are accompanied by tests for inequality in means ( $t$-tests) and variances (F-tests). The empirical findings provide a remarkable amount of support for our hypotheses. For instance, let us consider the CHF/USD results. On regular trading days (i.e. no bank holiday in Switzerland and in the US) the US dollar appreciates by an average of $7.2 \%$ during Swiss working hours. But when there is a holiday in Switzerland, the sell-pressure exerted by Swiss investors slackens. Buy-pressure in favour of the Swiss franc during Swiss trading hours is normally marginal; however in this exceptional case it prevails, and thus the dollar depreciates by $4.6 \%$. The opposite mechanism holds when the US rather than the Swiss market is in holiday. The sell-pressure against the Swiss franc normally exerted by Swiss investors during Swiss working hours exacerbates. Thus, the franc loses 19.8\% instead of its usual depreciation of 7.2\%. A mirror-image situation applies for US working hours: Swiss holidays lead to greater depreciation in the dollar. Overall, the findings on bank holiday effects provide additional support for the inventory hypothesis and offer further compelling evidence for the economic significance of the time-of-day phenomenon.

\section{Conclusion}

This study reveals a puzzling time-of-day pattern which affects foreign exchange markets. Domestic currencies tend to depreciate during domestic working time and to appreciate during the working hours of the counterpart country. This phenomenon is highly significant in statistical and economic terms. Its existence and persistence over a number of years contradicts the random walk and market efficiency hypothesis. On the one hand, one can try to explain these patterns by evoking liquidity premia, "Herstatt risk" or settlement issues. On the other hand, it is hard to explain why traders systematically incur larger transaction costs instead of taking full advantage of a round-the-clock global and liquid market. Furthermore, this anomaly appears to be profitable, even after accounting for reasonably competitive transaction costs and using elementary trading rules.

The explanation of these time-of-day trends seems to reside in microstructural and behavioural aspects of foreign exchange markets. The simple theoretical framework used in this study suggests two main explanations: inventory 
costs and information asymmetry. If we consider the marked regularity and well-defined price direction of the currency movements, the latter argument is hardly sustainable. Intraday time-series analysis also provides more support for the inventory hypothesis, although some asymmetric information effects are also perceptible. Consequently, we would tend to maintain that the combination of these two main factors accounts for this intraday pattern. First, domestic investors' portfolios are heavily biased towards domestic currencies. Second, currency markets are characterised by geographical and chronological segmentation. The conduct of domestic trading tends to cluster in domestic working hours. Thus, supply-pressure (demand-pressure) on the domestic currency during domestic (counterpart) working hours is transformed into cyclical inventory effects.

The puzzling evidence reported in this study raises significant questions that could be investigated in future research work. In particular, it would be useful to conduct a similar study to ours, studying order flow data for foreign exchange markets. Despite their limited accessibility, these data would enable researchers to empirically test some theoretical implications that we have left unexplored. 


\section{Appendix: theoretical model}

The notation below conforms the original Biais-Glosten-Spatt model (2005) that we follow closely. The trading mechanism is similar to a call auction in which the market order $Q$ is placed and then equilibrium achieved in a uniform-price auction. Consider a spot exchange rate of a currency pair as a risky asset. Denote its true value and its expected final value as $v$ and $\pi$, respectively. $v$ follows a random walk. Foreign exchange markets are both quote-driven and order-driven markets. Thus, liquidity suppliers can be dealers or brokers. ${ }^{25}$ We consider two types of agents: first, the liquidity demander who is the most active part in the trade which we hereinafter refer to as the "initiator" or "aggressor"; second, the liquidity provider who is more passive (also called "nonaggressor"). As described below, the former may have informational motives to trade. There are $N$ competitive liquidity suppliers who want to maximise their expected utlity function. The maximisation program for liquidity supplier $i$ is:

$$
\max _{q_{i}(p)} E U\left[(v-p) q_{i}(p)+I_{i} v-\frac{c}{2} q_{i}^{2}(p)\right]
$$

The initial currency endowment of liquidity supplier $i$ is $I_{i}$. ( $I=\sum_{n=1}^{N} \frac{I_{i}}{N}$ will be the average inventory position.) $\frac{c}{2} q_{i}^{2}$ is a quadratic cost function representing market-making administrative costs. We assume that the liquidity supplier has a CARA utility function with constant absolute risk aversion index is $\kappa$. Liquidity provider $i$ optimally designs his limit order schedule by choosing, for each possible price $P$, the quantity he will offer or demand: $q_{i}(p)$. By assuming exponential utility functions and normality, his objective function becomes:

$$
\max _{q_{i}(p)}\left(I_{i}-q_{i}\right) E[v \mid \theta]-q_{i} P-\frac{\kappa}{2}\left(I_{i}-q_{i}\right)^{2} \operatorname{Var}[v \mid \theta]-\frac{c}{2} q_{i}^{2}
$$

where $c$ is a constant handling cost and $\theta$ is the information revealed by the market order submitted by the aggressor who requires an immediate execution ( $\theta$ will be explicitly defined below). By solving the First Order Conditon, we find that $q_{i}=\frac{E[v \mid \theta]-p-\kappa \operatorname{Var}[v \mid \theta] I_{i}}{\kappa \operatorname{Var}[v \mid \theta]+c} \cdot \mu_{i}=E[v \mid \theta]-\kappa \operatorname{Var}[v \mid \theta] I_{i}$ can be seen as the marginal valuation for the liquidity supplier $i$. As market makers, the aggressor is a risk-averse agent with a CARA utility function and a constant absolute risk aversion index $\gamma$. He is endowed with domestic currency amounting to $L$. We assume that the aggressor comes from two groups of agents representing the domestic and foreign market participants. Let us call the endowment of the

\footnotetext{
${ }^{25} \mathrm{~A}$ unique utility function for dealers or brokers represents a limit in our approach.
} 
domestic and foreign group of investors $L_{D}$ and $L_{F}$, and $\omega_{D}$ and $\omega_{F}=1-\omega_{D}$ their proportion in the market. We can define $L$ as a random vector and the pair $\left[L_{D}, L_{F}\right]$ has a bivariate normal distribution. Each group has a bias towards its domestic currency. Thus, $L_{D}>0$ and $L_{F}<0$. From the rational liquidity supplier's perspective, $L$ mirrors the market pressure. Other things being equal, for the nonaggressor $E\left[\omega_{D} L_{D}+\omega_{F} L_{F}\right]=l=0$ means a balanced buy-sell pressure whereas $E[L]>0$ means an expected predominance of foreign currency demanders. This configures the stochastic nature of the investor's endowment. The aggressor is also endowed with an initial signal $s$ on the final value $v$. Thus, $v$ takes the form of $v=\pi+s+\epsilon . \pi$ is a constant and $E[s]=E[\epsilon]=0$, and $\sigma^{2}$ stands for the variance of $\epsilon$. The initiator places a market order to trade $Q$ shares. His objective function is:

$$
\max _{Q}(L+Q)(\pi+s)-Q p-\frac{\gamma}{2} \sigma^{2}(L+Q)^{2}
$$

By solving the First Order Condition, we find that $Q=\frac{\pi+s-p}{\gamma \sigma^{2}}-L . \theta=\pi+$ $s-\gamma \sigma^{2} L$ can be seen as the informed trader's marginal valuation. Once the market order is submitted, equilibrium is achieved in a simple uniform-price auction. The liquidity supplier takes into account the information content of the market order, namely the signal $s$ and the risk-sharing need, $L$, of the informed trader. By virtue of the Projection theorem, we can solve conditional expectations $E[v \mid \theta]=E[v]+\frac{\operatorname{Cov}(v, \theta)}{\operatorname{Var}(v)}(\theta-E[\theta])$ where $\delta=\frac{\operatorname{Cov}(v, \theta)}{\operatorname{Var}(v)}=\frac{\operatorname{Var}(s)}{\operatorname{Var}(s)+\left(\gamma \sigma^{2}\right)^{2} \operatorname{Var}(L)} . \delta$ represents the relative weight of the noise to signal and quantifies the magnitude of the adverse-selection problem. Since $E[\theta]=\pi-\gamma \sigma^{2} l$, the liquidity supplier's conditional expectation is:

$$
E[v \mid \theta]=(1-\delta) \pi+\delta\left(\theta-\gamma \sigma^{2} l\right)
$$

By setting market clearing as $\sum_{i=n}^{N} q_{i}(p)+Q=0$, we find the equilibrium price to be $P=\alpha+\beta \theta$ where:

$$
\alpha=\frac{\pi-\delta\left(\pi-\gamma \sigma^{2} l\right)-\kappa \operatorname{Var}[v \mid \theta] I}{1+\frac{c+\kappa \operatorname{Var}[v \mid \theta]}{N \gamma \sigma^{2}}}, \beta=\frac{\delta+\frac{c+\kappa \operatorname{Var}[v \mid \theta]}{N \gamma \sigma^{2}}}{1+\frac{c+\kappa \operatorname{Var}[v \mid \theta]}{N \gamma \sigma^{2}}}
$$

Note that $l$ affects only the intercept and not the slope of the price function. Since the equilibrium price is linear in $\theta$, and $\theta$, in turn, is linear in $Q$ and $L$, we find that:

$$
P=\frac{\alpha}{1-\beta}+\frac{\beta}{1-\beta} \gamma \sigma^{2} Q, P=(\alpha+\beta \pi+\beta s)-\beta \gamma \sigma^{2} L
$$




\section{References}

[1] Andersen, T. G., and T. Bollerslev (1997), Intraday Periodicity and Volatility Persistence in Financial Markets, Journal of Empirical Finance 4, 115158.

[2] Andersen, T. G., and T. Bollerslev (1998), Deutsche Mark-Dollar Volatility: Intraday Activity Patterns, Macroeconomic Announcements, and Longer Run Dependencies, Journal of Finance 53, 219-265.

[3] Andersen, T. G., T. Bollerslev, F. X. Diebold and C. Vega (2003), Micro Effects of Macro Announcements: Real-Time Price Discovery in Foreign Exchange, American Economic Review 93, 38-62.

[4] Baillie, R. T., and T. Bollerslev (1998), Intra-Day and Inter-Market Volatility in Foreign Exchange Rates, Review of Economic Studies 58, 565-585.

[5] Bank for International Settlements (2005), Triennial Central Bank Survey: Foreign Exchange and Derivatives Market Activity in 2004, Basle, Bank for International Settlements.

[6] Bauwens, L., W. Ben Omrane and P. Giot (2005), News Announcements, Market Activity and Volatility in the Euro-Dollar Foreign Exchange Market, Journal of International Money and Finance 24, 1108-1125.

[7] Bessembinder, H. (1994), Bid-Ask Spread in the Interbank Foreign Exchange Markets, Journal of Financial Economics 35, 317-348.

[8] Biais, B, L. Glosten, and C. Spatt (2005), Market Microstructure: a Survey of Microfoundations, Empirical Results, and Policy Implications, Journal of Financial Markets 8, 217-264.

[9] Bjørnnes, G. H., and D. Rime (2005), Dealer Behaviour and Trading Systems in Foreign Exchange Markets, Journal of Financial Economics 75, 571-605.

[10] Bollerslev, T., and I. Domowitz (1993), Trading Patterns and Prices in the Interbank Foreign Exchange Market, Journal of Finance 48, 1421-1443.

[11] Breedon, F., and P. Vitale (2005), An Empirical Study of Liquidity and Information Effects of Order Flow on Exchange Rates, CEPR Working Paper.

[12] Cao, H. H., M. D. Evans and R. K. Lyons (2006), Inventory Information, Journal of Business 79, 325-363. 
[13] Dacorogna, M. M., U. A. Müller, R. J. Nagler, R. B. Olsen and O. Pictet (1993), A Geographical Model fort he Daily and Weekly Seasonal Volatility in the Foreign Exchange Market, Journal of International Money and Finance 12, 413-438.

[14] Dominguez, K. M. (1998), Central bank intervention and exchange rate volatility, Journal of International Money and Finance 17, 161-190.

[15] Ederington, L. H., and J. H. Lee (1993), How Markets Process Information: News Releases and Volatility, Journal of Finance 48, 1161-1191.

[16] Engle, R. F., T. Ito and W. Lin (1990), Meteor Showers or Heat Waves? Heteroskedastic Intraday Volatility in the Foreign Exchange Market, Econometrica 58, 525-542..

[17] Evans, M. D. D., and R. K. Lyons (2002a), Order Flow and Exchange Rate Determinants, Journal of Political Economy 110, 170-180.

[18] Evans, M. D. D., and R. K. Lyons (2002b), Informational Integration and FX Trading, Journal of International Money and Finance 21, 807-831.

[19] Evans, M. D. D., and R. K. Lyons (2005), Do Currency Markets Absorb News Quickly?, Journal of International Money and Finance 24, 197-217.

[20] Flood, M. (1994), Market Structure and Inefficiency in the Foreign Exchange Market, Journal of International Money and Finance 13, 131-158.

[21] French, K. R. (1980), Stock Returns and the Weekend Effect, Journal of Financial Economics 8, 55-69.

[22] Froot, K. A. (1991), Japanese Foreign Direct Investment, NBER Working Paper \# 3737.

[23] Goodhart, C., T. Ito and R. Payne (1996), One Day in June 1993: A Study of the Working of the Reuters 2000-2 Electronic Foreign Exchange Trading System, in J.A. Frankel, G. Galli, and A. Giovannini (eds.) The Microstructure of Foreign Exchange Markets, Chicago: The University Chicago Press: 107-179.

[24] Goodhart, C., R. Love, R. Payne and D. Rime (2002), Analysis of Spread in the Dollar/Euro and Deutsche-Mark/Dollar Foreign Exchange Markets, Economic Policy 17, 536-552. 
[25] Hsieh, D. A., and A. W. Kleidon (1996), Bid-Ask Spreads in Foreign Exchange Markets: Implication of Asymmetric Information, in J.A. Frankel, G. Galli, and A. Giovannini (eds.) The Microstructure of Foreign Exchange Markets, Chicago: The University Chicago Press: 41-67.

[26] Ito, T. (1987), The Intra-daily Exchange Rate Dynamics and Monetary Policies After the G5 Agreement, Journal of the Japanese and International Economics 1, 275-298.

[27] Ito, T., and Y. Hashimoto (2005), Intra-day Seasonality in Activities of the Foreign Exchange Markets: Evidence from the Electronic Broking System, ISER Working Paper.

[28] Ito, T., and V. V. Roley (1987), News from the U.S. and the Japan which Moves the Yen/Dollar Exchange Rate?, Journal of Monetary Economics 19, 255-278.

[29] Ito, T., and V. V. Roley (1991), Intraday Yen/Dollar Exchange Rate Movements: News or Noise?, Journal of International Financial Markets, Institutions and Money 1, 1-31.

[30] Lewis, K. K. (1999), Trying to Explain Home Bias in Equities and Consumption, Journal of Economic Literature 37, 571-608.

[31] Lyons, R. K. (1995), Tests of Microstructural Hypotheses in the Foreign Exchange Market, Journal of Financial Economics 39, 321-351.

[32] Lyons, R. K. (1998), Profits and Position Controls: a Week of FX Dealing, Journal of International Money \& Finance 17, 97-115.

[33] Lyons, R. K. (2001), The Microstructure Approach to Exchange Rates, MIT Press, Cambridge, Massachusetts.

[34] Marsh, I., and C. O'Rourke (2005), Customer Order Flow and Exchange Rate Movements: Is There Really Information Content?, Working Paper.

[35] Martens, M., and P. Kofman, , 1998. The Inefficiency of Reuters Foreign Exchange Quotes, Journal of Banking and Finance 22, 347-366.

[36] Massa, M., and A. Simonov (2006), Hedging, Familiarity and Portfolio Choice, Review of Financial Studies 19, 633-685.

[37] Menkhoff, L., and M. Schmeling (2006), Local Information in Foreign Exchange Markets, Discussion Paper \#331 University of Hannover. 
[38] Müller, U. A., M. M. Dacorogna, R. B. Olsen, O. V. Pictet, M. Schwarz and C. Morgenegg (1990), Statistical Study of Foreign Exchange Rates, Empirical Evidence of a Price Change Law, and Intraday Analysis, Journal of Banking and Finance 14, 1189-1208.

[39] Olsen, R. B., A. U. A. Müller, M. M. Dacorogna, and O. V. Pictet \& R. R. Davé \& D. M. Guillaume (1997), From the bird's eye to the microscope: A survey of new stylised facts of the intra-daily foreign exchange markets, Finance \& Stochastics 1, 95-129.

[40] Osler, C. L., A. Mende, and L. Menkhoff (2006), Price Discovery in Currency Markets, Working Paper, EFA Meetings.

[41] Payne, R. (2003), Informed Trade in Spot Foreign Exchange Markets: an Empirical Investigation, Journal of International Economics 61, 307-329.

[42] Sarno, L., and M. P. Taylor (2001), The Microstructure of the ForeignExchange Market: a Selective Survey of the Literature, Working Paper, Princeton Studies in International Economics No. 89.

[43] Shirayev, A. (1978), Optimal Stopping Rules, New York: Springer-Verlag. 
Table 1: Weekend definitions and official holidays by country.

Panel A: Weekend definitions.

\begin{tabular}{|c|c|c|c|c|c|c|c|}
\hline \multicolumn{5}{|c|}{ Beginning } & \multicolumn{3}{|c|}{ End } \\
\hline Ccy & GMT & Local ccy 1 & Local ccy 2 & GMT & Local ccy 1 & Local ccy 2 & $\mathrm{~h}$ excluded \\
\hline CHFUSD & Mon 5:00 & Mon 6:00 & Sun $24: 00$ & Fri 23:00 & Fri 24:00 & Fri $18: 00$ & 54 \\
\hline DEMUSD & Mon 5:00 & Mon 6:00 & Sun $24: 00$ & Fri 23:00 & Fri 24:00 & Fri $18: 00$ & 54 \\
\hline EURUSD & Mon 5:00 & Mon 6:00 & Sun $24: 00$ & Fri 23:00 & Fri 24:00 & Fri $18: 00$ & 54 \\
\hline JPYEUR & Sun $21: 00$ & Mon 6:00 & Sun 22:00 & Fri $17: 00$ & Sat 2:00 & Fri 18:00 & 52 \\
\hline JPYUSD & Sun 21:00 & Mon 6:00 & Sun $16: 00$ & Fri 23:00 & Sat 8:00 & Fri $18: 00$ & 46 \\
\hline
\end{tabular}

Panel B: Official holidays, by country.

\begin{tabular}{llll} 
Germany & Japan & Switzerland & US \\
\hline New Year & New Year & New Year & New Year \\
Good Friday & Bank holiday (2.-3. Jan) & Good Friday & Martin Luther King Day \\
Easter Monday & Coming of Age Day & Easter Monday & Presidents' Day \\
Labour Day & Founding of the Nation & Ascension & Memorial Day \\
Ascension & Vernal equinox Day & Whit Monday & Independence Day \\
Whit Monday & Greenery Day & Confederation Day & Labor Day \\
Union Day & Constitution Day & Christmas Day & Columbus Day \\
Christmas Day & Children's Day & St Stephan's Day & Veterans Day \\
Boxing Day & Marine Day & New Year's Eve & Thanksgiving Day \\
New Years Eve & Respect-for-the-aged Day & & Christmas Day \\
& Autumn equinox Day & & \\
& Health-Sports Day & & \\
& Culture Day & & \\
& Labour Day & & \\
& Thanksgiving Day & & \\
& Ordinary holiday & & \\
& The Emperor's Day &
\end{tabular}


Table 2: Descriptive statistics of currency performance over four-hour intraday periods, round-the-clock.

This table shows the descriptive statistics for intradaily and daily returns, excluding weekends, for each currency pair. Intraday (log) returns are calculated over non-overlapping 4-hour periods. The first row shows the time of the day (GMT) and the second row indicates which country or region is working during the different hours of the day. The table shows the $t$-test and Chi-square for testing the null hypothesis that there is equality in means and medians, and Q-statistic for testing the null hypothesis that there is no autocorrelation at lag 1. Significance at $1 \%, 5 \%$ and $10 \%$ is denoted by $* * *, * *$ and $*$, respectively.

\begin{tabular}{|c|c|c|c|c|c|c|c|}
\hline EST & $19-23$ & $23-3$ & $3-7$ & $7-11$ & $11-15$ & $15-19$ & Whole \\
\hline GMT & $0-4$ & $4-8$ & $8-12$ & $12-16$ & $16-20$ & $20-24$ & Daily \\
\hline Working time & JP & JP - EU & $\mathrm{EU}$ & EU - US & US & US & \\
\hline \multicolumn{8}{|l|}{ CHF/USD } \\
\hline Mean & $-1.00 \%$ & $3.1 \% * *$ & $7.2 \%$ *** & $-6.1 \% * * *$ & $-3.0 \% * *$ & $-0.80 \%$ & $-0.10 \%$ \\
\hline Median & $-1.00 \%$ & $2.8 \% * * *$ & $7.9 \% * * *$ & $-3.9 \% * * *$ & $0.00 \%$ & $0.00 \%$ & $0.00 \%$ \\
\hline Maximum & 2.709 & 2.811 & 4.319 & 7.108 & 4.368 & 2.048 & 7.96 \\
\hline Minimum & -3.229 & -3.585 & -6.091 & -5.405 & -5.822 & -3.885 & -7.382 \\
\hline Std. Dev. & $3.3 \%$ & $5.1 \%$ & $6.7 \%$ & $5.4 \%$ & $2.6 \%$ & $2.9 \%$ & $4.7 \%$ \\
\hline Skewness & -0.12 & -0.16 & -0.25 & -0.05 & -0.25 & -0.44 & -0.21 \\
\hline Kurtosis & 8.28 & 6.09 & 6.14 & 5.34 & 6.41 & 8.66 & 6.05 \\
\hline \# of Obs & 3274 & 3274 & 3274 & 3274 & 2620 & 2620 & 74652 \\
\hline Q-Stat 1 & $2.89 *$ & 0.15 & $7.96 * * *$ & $31.90 * * *$ & $4.77 * *$ & 2.58 & - \\
\hline \multicolumn{8}{|l|}{ DEM/USD } \\
\hline Mean & $0.50 \%$ & $1.60 \%$ & $5.0 \% * * *$ & $-5.8 \% * * *$ & $0.30 \%$ & $0.30 \%$ & $0.30 \%$ \\
\hline Median & $0.80 \%$ & $0.00 \%$ & $3.8 \% * * *$ & $-6.6 \% * * *$ & $0.80 \%$ & $0.00 \%$ & $0.00 \%$ \\
\hline Maximum & 1.753 & 2.315 & 3.475 & 6.202 & 4.753 & 1.821 & 6.8 \\
\hline Minimum & -2.49 & -3.212 & -4.447 & -4.849 & -4.928 & -2.95 & -5.763 \\
\hline Std. Dev. & $2.7 \%$ & $4.1 \%$ & $5.7 \%$ & $5.0 \%$ & $2.5 \%$ & $2.8 \%$ & $4.1 \%$ \\
\hline Skewness & -0.34 & 0.08 & -0.03 & 0.22 & -0.27 & -0.75 & -0.1 \\
\hline Kurtosis & 6.7 & 6.54 & 7.15 & 6.83 & 8.71 & 10.65 & 7.63 \\
\hline \# of Obs & 1250 & 1561 & 1561 & 1561 & 1561 & 1249 & 35595 \\
\hline Q-Stat 1 & 1.07 & 0.02 & $27.86 * * *$ & $18.86^{* * * *}$ & $6.51 * *$ & 0.87 & - \\
\hline \multicolumn{8}{|l|}{ EUR/USD } \\
\hline Mean & $-1.40 \%$ & $-3.10 \%$ & $10.3 \% * * *$ & $-2.30 \%$ & $-6.4 \% * * *$ & $1.50 \%$ & $-0.30 \%$ \\
\hline Median & $0.00 \%$ & $-1.4 \% *$ & $10.8 \% * * *$ & $1.40 \%$ & $-5.7 \% * * *$ & $1.10 \%$ & $0.00 \%$ \\
\hline Maximum & 2.569 & 2.758 & 4.034 & 3.433 & 4.313 & 1.641 & 5.072 \\
\hline Minimum & -1.751 & -3.732 & -4.15 & -4.645 & -4.828 & -2.379 & -8.956 \\
\hline Std. Dev. & $3.2 \%$ & $5.1 \%$ & $6.2 \%$ & $4.6 \%$ & $2.4 \%$ & $2.7 \%$ & $4.4 \%$ \\
\hline Skewness & 0.2 & -0.38 & -0.14 & -0.21 & -0.14 & -0.06 & -0.22 \\
\hline Kurtosis & 6.29 & 6.67 & 5.31 & 4.4 & 6.41 & 6.08 & 5.49 \\
\hline \# of Obs & 1371 & 1713 & 1713 & 1713 & 1713 & 1371 & 39060 \\
\hline Q-Stat 1 & 0.22 & $3.48 *$ & 0.01 & $19.70^{* * * *}$ & 0.83 & 1.24 & - \\
\hline \multicolumn{8}{|l|}{ JPY/EUR } \\
\hline Mean & $2.8 \% *$ & $-2.80 \%$ & $-8.0 \% * * *$ & $-0.90 \%$ & $6.2 \% * * *$ & $0.10 \%$ & $-0.60 \%$ \\
\hline Median & $1.30 \%$ & $-1.4 \% *$ & $-4.2 \% * * *$ & $0.00 \%$ & $5.7 \% * * *$ & $0.90 \%$ & $0.00 \%$ \\
\hline Maximum & 4.791 & 4.961 & 4.239 & 5.525 & 3.88 & 4.627 & 8.942 \\
\hline Minimum & -7.435 & -4.56 & -5.09 & -4.791 & -6.033 & -9.409 & -9.409 \\
\hline Std. Dev. & $4.2 \%$ & $6.0 \%$ & $6.4 \%$ & $4.8 \%$ & $3.5 \%$ & $4.6 \%$ & $4.9 \%$ \\
\hline Skewness & -0.07 & -0.01 & -0.33 & -0.08 & -0.31 & -2.68 & -0.18 \\
\hline Kurtosis & 13.16 & 8.23 & 5.96 & 5.51 & 8.26 & 51.72 & 7.3 \\
\hline \# of Obs & 1713 & 1713 & 1713 & 1713 & 1370 & 1712 & 39836 \\
\hline Q-Stat 1 & 2.91 & 0.64 & 0.03 & $7.70 * * *$ & 0.95 & 0.55 & - \\
\hline \multicolumn{8}{|l|}{ JPY/USD } \\
\hline Mean & $2.7 \% * *$ & $-2.40 \%$ & $-0.60 \%$ & $-4.0 \% * * *$ & $2.8 \% * *$ & $0.30 \%$ & $-0.20 \%$ \\
\hline Median & $1.3 \%^{*}$ & $-1.3 \% *$ & $0.00 \%$ & $-3.7 \% * * *$ & $2.5 \% * *$ & $1.10 \%$ & $0.00 \%$ \\
\hline Maximum & 5.521 & 4.587 & 7.894 & 6.045 & 9.862 & 5.384 & 14.365 \\
\hline Minimum & -9.998 & -6.118 & -15.034 & -8.348 & -8.773 & -4.153 & -21.739 \\
\hline Std. Dev. & $3.9 \%$ & $5.4 \%$ & $5.1 \%$ & $5.3 \%$ & $3.3 \%$ & $4.8 \%$ & $4.7 \%$ \\
\hline Skewness & -0.66 & -0.34 & -1.89 & -0.42 & -0.04 & -0.32 & -0.75 \\
\hline Kurtosis & 17.4 & 13.63 & 39.72 & 11.03 & 15.18 & 15.02 & 24.96 \\
\hline \# of Obs & 3274 & 3274 & 3274 & 3274 & 3274 & 3597 & 79219 \\
\hline Q-Stat 1 & $11.26^{* * *}$ & $9.43^{* * *}$ & 0.04 & $8.87 * * *$ & $4.12 * *$ & 0 & - \\
\hline
\end{tabular}


Table 3: Four-hour returns patterns across working days.

For each currency pair, this table shows average daily and intradaily returns during the working week. The table shows the $t$-test for testing the null hypothesis that there is equality in means between the average return over a specific 4-hour period of a given day of the week and the average return during the same intraday period of all the working days. Significance at $1 \%$ and $5 \%$ is denoted by $* *$ and $*$, respectively.

\begin{tabular}{|c|c|c|c|c|c|c|}
\hline \multicolumn{7}{|l|}{$\begin{array}{l}\text { CHF/USD } \\
\text { Time }\end{array}$} \\
\hline Time & Mon & Tue & Wed & Thu & Fri & Intraday \\
\hline From 0 to 4 & & $0.90 \%$ & $-1.20 \%$ & $-4.00 \%$ & $1.20 \%$ & $-1.00 \%$ \\
\hline From 4 to 8 & $2.90 \%$ & $1.80 \%$ & $2.60 \%$ & $2.60 \%$ & $5.00 \%$ & $2.40 \%$ \\
\hline From 8 to 12 & $10.2 \% *$ & $2.4 \% *$ & $3.40 \%$ & $6.90 \%$ & $7.00 \%$ & $7.20 \%$ \\
\hline From 12 to 16 & $-4.60 \%$ & $-3.40 \%$ & $-0.80 \%$ & $-7.10 \%$ & $-7.00 \%$ & $-5.20 \%$ \\
\hline From 16 to 20 & $-2.20 \%$ & $-6.5 \% *$ & $-1.30 \%$ & $-7.9 \% * *$ & $1.1 \% * *$ & $-3.20 \%$ \\
\hline From 20 to 24 & $-0.30 \%$ & $-0.50 \%$ & $-0.40 \%$ & $-2.30 \%$ & & $-0.80 \%$ \\
\hline Day-effect & $1.20 \%$ & $-0.80 \%$ & $0.40 \%$ & $-1.90 \%$ & $0.80 \%$ & $0.00 \%$ \\
\hline \multicolumn{7}{|l|}{ DEM/USD } \\
\hline Time & Mon & Tue & Wed & Thu & Fri & Intraday \\
\hline From 0 to 4 & & $1.80 \%$ & $0.10 \%$ & $-3.00 \%$ & $3.20 \%$ & $0.50 \%$ \\
\hline From 4 to 8 & $3.60 \%$ & $1.10 \%$ & $-0.80 \%$ & $-2.20 \%$ & $6.50 \%$ & $1.60 \%$ \\
\hline From 8 to 12 & $7.70 \%$ & $-0.10 \%$ & $9.7 \% * *$ & $6.80 \%$ & $1.0 \% *$ & $5.00 \%$ \\
\hline From 12 to 16 & $-11.7 \% * *$ & $1.7 \% * *$ & $-4.80 \%$ & $-6.00 \%$ & $-8.30 \%$ & $-5.80 \%$ \\
\hline From 16 to 20 & $3.20 \%$ & $-1.20 \%$ & $0.70 \%$ & $-10.8 \% * *$ & $9.8 \% * *$ & $0.30 \%$ \\
\hline From 20 to 24 & $-1.30 \%$ & $1.40 \%$ & $1.30 \%$ & $-0.30 \%$ & & $0.30 \%$ \\
\hline Day-effect & $0.50 \%$ & $0.40 \%$ & $0.90 \%$ & $-2.70 \%$ & $2.30 \%$ & $0.00 \%$ \\
\hline \multicolumn{7}{|l|}{ EUR/USD } \\
\hline Time & Mon & Tue & Wed & Thu & Fri & Intraday \\
\hline From 0 to 4 & & $1.00 \%$ & $-2.70 \%$ & $-3.10 \%$ & $-0.60 \%$ & $-1.40 \%$ \\
\hline From 4 to 8 & $-5.20 \%$ & $-3.90 \%$ & $-6.10 \%$ & $-0.60 \%$ & $0.50 \%$ & $-3.10 \%$ \\
\hline From 8 to 12 & $13.7 \% *$ & $8.70 \%$ & $14.6 \% * *$ & $9.30 \%$ & $5.3 \% * *$ & $10.30 \%$ \\
\hline From 12 to 16 & $1.5 \% *$ & $-10.5 \% * *$ & $2.6 \% *$ & $-4.70 \%$ & $-0.70 \%$ & $-2.30 \%$ \\
\hline From 16 to 20 & $-5.80 \%$ & $-7.40 \%$ & $-3.90 \%$ & $-8.70 \%$ & $-6.20 \%$ & $-6.40 \%$ \\
\hline From 20 to 24 & $4.40 \%$ & $-0.20 \%$ & $2.90 \%$ & $-1.00 \%$ & & $1.50 \%$ \\
\hline Day-effect & $1.10 \%$ & $-1.60 \%$ & $1.00 \%$ & $-1.00 \%$ & $-0.80 \%$ & $0.00 \%$ \\
\hline \multicolumn{7}{|l|}{ JPY/EUR } \\
\hline Time & Mon & Tue & Wed & Thu & Fri & Intraday \\
\hline From 0 to 4 & $-3.7 \% *$ & $3.40 \%$ & $2.50 \%$ & $1.50 \%$ & $10.5 \%$ ** & $2.90 \%$ \\
\hline From 4 to 8 & $-1.70 \%$ & $-0.20 \%$ & $-0.40 \%$ & $-7.1 \% *$ & $-4.50 \%$ & $-2.80 \%$ \\
\hline From 8 to 12 & $-15.7 \% * *$ & $-7.40 \%$ & $-5.70 \%$ & $-5.10 \%$ & $-5.30 \%$ & $-7.80 \%$ \\
\hline From 12 to 16 & $2.8 \% * *$ & $1.60 \%$ & $-5.7 \% * *$ & $1.50 \%$ & $-4.6 \% *$ & $-0.90 \%$ \\
\hline From 16 to 20 & $6.10 \%$ & $-0.10 \%$ & $8.00 \%$ & $10.90 \%$ & & $6.20 \%$ \\
\hline From 20 to 24 & $0.50 \%$ & $2.40 \%$ & $-1.90 \%$ & $6.70 \%$ & & $0.20 \%$ \\
\hline Day-effect & $-2.60 \%$ & $0.00 \%$ & $-0.10 \%$ & $0.10 \%$ & $0.50 \%$ & $-0.60 \%$ \\
\hline \multicolumn{7}{|l|}{ JPY/USD } \\
\hline Time & Mon & Tue & Wed & Thu & Fri & Intraday \\
\hline From 0 to 4 & $-1.5 \% *$ & $2.60 \%$ & $2.50 \%$ & $-3.5 \% * *$ & $13.6 \% * *$ & $2.70 \%$ \\
\hline From 4 to 8 & $-2.40 \%$ & $-3.00 \%$ & $-4.50 \%$ & $-0.10 \%$ & $-1.80 \%$ & $-2.50 \%$ \\
\hline From 8 to 12 & $0.40 \%$ & $0.80 \%$ & $3.4 \% * *$ & $-3.30 \%$ & $-4.5 \% *$ & $-0.60 \%$ \\
\hline From 12 to 16 & $-5.20 \%$ & $-4.80 \%$ & $-0.70 \%$ & $-8.1 \% * *$ & $-1.00 \%$ & $-4.00 \%$ \\
\hline From 16 to 20 & $4.70 \%$ & $-5.8 \% * *$ & $4.60 \%$ & $3.90 \%$ & $6.6 \% *$ & $2.80 \%$ \\
\hline From 20 to 24 & $2.50 \%$ & $-1.90 \%$ & $0.50 \%$ & $-0.60 \%$ & $-0.40 \%$ & $0.30 \%$ \\
\hline Day-effect & $-0.50 \%$ & $-1.80 \%$ & $1.10 \%$ & $-2.20 \%$ & $2.50 \%$ & $0.00 \%$ \\
\hline
\end{tabular}


Table 4: Strategy performance.

For each currency pair, this table shows the performance of different trading strategies implemented at specific times during the working week. The long (short) trading rule takes a 4-hour long (short) position in domestic currency each working day at times which coincide with pre-established foreign (domestic) working hours. The long-short strategy combines the first two rules. The fourth and fifth trading rules implement a short-long strategy on a specific day in the working week, i.e. Mondays, Thursdays or Fridays. Taking annualised values, performance is evaluated in terms of the mean return, standard deviation and Sharpe ratio. Columns 5-7 show the results of the market model estimation where the dependent variable is the intraday return on a given day resulting from one of the five trading strategies, while the explanatory variables are a constant (alpha) and the daily return on the respective currency pair (beta). R-2 indicates the adjusted R-squared. Column 8 shows the break-even cost for each currency strategy, i.e. the implicit maximum cost necessary to avoid incurring losses. Using the Reuters representative quotes, the last column shows the average bid-ask spread size surrounding the beginning and end time of the intraday holding periods. The t-statistic is used to test the hypothesis that a regression coefficient is equal to zero. Significance at $1 \%$ and $5 \%$ is denoted by $* *$ and $*$, respectively.

\begin{tabular}{|c|c|c|c|c|c|c|c|c|}
\hline CHF/USD & Mean & StDev & SR & Alpha & Beta & $\mathrm{R}-2$ & $\begin{array}{c}\text { Break-even } \\
\text { Cost }\end{array}$ & $\begin{array}{c}\text { Reuters } \\
\text { Spread }\end{array}$ \\
\hline Long 8:00-12:00 & $7.21 \%$ & $5.12 \%$ & 1.41 & $0.073^{* *}$ & $0.196^{* *}$ & $18.6 \%$ & 2.8 & 6.2 \\
\hline Short 12:00-16:00 & $5.17 \%$ & $6.68 \%$ & 0.77 & $0.049^{* *}$ & $-0.377 * *$ & $40.3 \%$ & 2.0 & 5.6 \\
\hline Long+Short & $12.38 \%$ & $8.43 \%$ & 1.47 & $0.123^{* *}$ & $-0.181 * *$ & $5.8 \%$ & 2.4 & 5.9 \\
\hline Long+Short Mondays & $14.76 \%$ & $7.29 \%$ & 2.02 & $0.156^{* *}$ & $-0.105^{*}$ & $2.1 \%$ & 14.2 & 5.9 \\
\hline Long+Short Thursday & $13.95 \%$ & $9.14 \%$ & 1.53 & $0.113^{* *}$ & $-0.218 * *$ & $7.3 \%$ & 13.4 & 5.9 \\
\hline DEM/USD & Mean & StDev & SR & Alpha & Beta & R-square & Break-even & R. Spread \\
\hline Long 8:00-12:00 & $5.01 \%$ & $4.09 \%$ & 1.22 & $0.048^{* *}$ & $0.075^{* *}$ & $3.4 \%$ & 1.9 & 7.4 \\
\hline Short 12:00-16:00 & $5.80 \%$ & $5.71 \%$ & 1.02 & $0.059^{* *}$ & $-0.087 * *$ & $2.3 \%$ & 2.2 & 7.4 \\
\hline Long+Short & $10.81 \%$ & $6.98 \%$ & 1.55 & $0.108^{* *}$ & -0.011 & $0.9 \%$ & 2.1 & 7.3 \\
\hline Long+Short Mondays & $19.39 \%$ & $5.45 \%$ & 3.56 & $0.197 * *$ & $-0.065^{*}$ & $1.2 \%$ & 18.6 & 7.3 \\
\hline Long+Short Thursday & $12.81 \%$ & $7.89 \%$ & 1.62 & $0.011^{* *}$ & $-0.252^{* *}$ & $11.1 \%$ & 12.3 & 7.4 \\
\hline EUR/USD & Mean & StDev & SR & Alpha & Beta & R-square & Break-even & R. Spread \\
\hline Long 8:00-12:00 & $10.32 \%$ & $5.12 \%$ & 2.02 & $0.107^{* *}$ & $0.215^{* *}$ & $19.3 \%$ & 4.0 & 3.1 \\
\hline Short 16:00-20:00 & $6.39 \%$ & $4.63 \%$ & 1.38 & $0.060^{* *}$ & $-0.223^{* *}$ & $25.5 \%$ & 2.5 & 2.9 \\
\hline Long+Short & $16.71 \%$ & $6.95 \%$ & 2.41 & $0.167^{* *}$ & -0.009 & $0.8 \%$ & 3.2 & 3.0 \\
\hline Long+Short Mondays & $19.48 \%$ & $6.67 \%$ & 2.92 & $0.186^{* *}$ & $0.120^{* *}$ & $2.4 \%$ & 18.7 & 2.9 \\
\hline Long+Short Thursday & $18.01 \%$ & $7.18 \%$ & 2.51 & $0.177^{* *}$ & -0.032 & $0.2 \%$ & 17.3 & 2.9 \\
\hline JPY/EUR & Mean & StDev & SR & Alpha & Beta & R-square & Break-even & R. Spread \\
\hline Long 0:00-4:00 & $2.84 \%$ & $4.59 \%$ & 0.62 & $0.032 *$ & $0.132 * *$ & $11.5 \%$ & 1.1 & 6.1 \\
\hline Short 8:00-12:00 & $8.00 \%$ & $5.96 \%$ & 1.34 & $0.074^{* *}$ & $-0.249 * *$ & $24.3 \%$ & 3.1 & 6.5 \\
\hline Long+Short & $10.84 \%$ & $7.43 \%$ & 1.46 & $0.105^{* *}$ & $-0.117 * *$ & $3.5 \%$ & 2.1 & 6.4 \\
\hline Long+Short Mondays & $11.84 \%$ & $9.05 \%$ & 1.31 & $0.122^{* *}$ & -0.108 & $2.5 \%$ & 11.4 & 6.2 \\
\hline Long+Short Fridays & $15.75 \%$ & $7.14 \%$ & 2.2 & $0.158^{* *}$ & $-0.153^{* *}$ & $6.5 \%$ & 15.1 & 6.2 \\
\hline JPY/USD & Mean & StDev & SR & Alpha & Beta & R-square & Break-even & R. Spread \\
\hline Long 0:00-4:00 & $2.73 \%$ & $4.79 \%$ & 0.57 & 0.021 & $0.195^{* *}$ & $21.5 \%$ & 1.1 & 3.1 \\
\hline Short 12:00-16:00 & $3.97 \%$ & $5.12 \%$ & 0.78 & 0.032 & $-0.176 * *$ & $18.5 \%$ & 1.5 & 2.9 \\
\hline Long+Short & $6.70 \%$ & $6.94 \%$ & 0.96 & 0.053 & 0.019 & $0.1 \%$ & 1.3 & 3.0 \\
\hline Long+Short Mondays & $3.66 \%$ & $7.27 \%$ & 0.5 & $0.156^{* *}$ & $0.205^{* *}$ & $7.2 \%$ & 3.5 & 3.1 \\
\hline Long+Short Fridays & $14.61 \%$ & $7.11 \%$ & 2.06 & $0.142^{* *}$ & 0.036 & $0.4 \%$ & 14.0 & 3.0 \\
\hline
\end{tabular}


Table 5: The SUR model regression on 4-hour intraday returns.

This table shows the estimates from a Seemingly Unrelated Regression (SUR) model that analyses intraday price dynamics. The first (second) column titled $\mathrm{Y}(\mathrm{X})$ reports the elements in a matrix of the response (explanatory) variables. The day is broken down into six 4-hour periods. Thus, $r_{t}^{h-h+4}$ designates the return from intraday time $h$ to four hours ahead (GMT) on day $t$. The $t$-statistic is used to test the hypothesis that a regression coefficient is equal to zero. Significance at $1 \%$ and $5 \%$ is denoted by $* *$ and $*$, respectively. R squares are also reported.

\begin{tabular}{|c|c|c|c|c|c|c|}
\hline $\mathrm{Y}$ & $\mathrm{X}$ & CHFUSD & DEMUSD & EURUSD & JPYEUR & JPYUSD \\
\hline \multirow[t]{8}{*}{$\mathrm{R}_{\mathrm{t}}^{20-24}$} & Constant & -0.001 & 0.002 & 0.004 & -0.001 & 0 \\
\hline & $\mathrm{R}_{\mathrm{t}}^{16-20}$ & $-0.018^{*}$ & $-0.023^{*}$ & -0.011 & $-0.057 * *$ & $-0.050^{* *}$ \\
\hline & $\mathrm{R}_{\mathrm{t}}^{12-16}$ & 0.009 & 0.005 & 0.002 & -0.008 & $-0.023^{*}$ \\
\hline & $\mathrm{R}_{\mathrm{t}}^{8-12}$ & $-0.040^{* *}$ & $-0.036^{* *}$ & -0.004 & $-0.086 * *$ & $-0.055^{* *}$ \\
\hline & $\mathrm{R}_{\mathrm{t}}^{4-8}$ & -0.004 & -0.01 & 0.003 & 0.005 & $-0.034 *$ \\
\hline & $\mathrm{R}_{\mathrm{t}}^{0-24}$ & 0.011 & 0.014 & $-0.178^{* *}$ & -0.01 & $0.024 *$ \\
\hline & $\mathrm{R}_{\mathrm{t}-1}{ }^{20-24}$ & $-0.040^{*}$ & -0.02 & -0.034 & 0.024 & 0.02 \\
\hline & R2 & $1.20 \%$ & $0.90 \%$ & $4.20 \%$ & $2.70 \%$ & $1.90 \%$ \\
\hline \multirow[t]{8}{*}{$\mathrm{R}_{\mathrm{t}}{ }^{16-20}$} & Constant & $-0.012 *$ & 0.002 & $-0.023 * *$ & $0.020^{* *}$ & $0.012 *$ \\
\hline & $\mathrm{R}_{\mathrm{t}}^{12-16}$ & $0.068^{* *}$ & $0.063^{* *}$ & $0.057 * *$ & $0.040^{*}$ & $0.045 *$ \\
\hline & $\mathrm{R}_{\mathrm{t}}^{8-12}$ & 0.01 & 0.026 & -0.009 & -0.011 & -0.01 \\
\hline & $\mathrm{R}_{\mathrm{t}}^{4-8}$ & 0.053 & 0.042 & 0.016 & $0.049 *$ & 0.031 \\
\hline & $\mathrm{R}_{\mathrm{t}}^{0-4}$ & -0.003 & 0.022 & 0.089 & 0.017 & $0.039 *$ \\
\hline & $\mathrm{R}_{\mathrm{t}-1}{ }^{20-24}$ & -0.057 & -0.002 & -0.092 & 0.056 & $0.094^{* *}$ \\
\hline & $\mathrm{R}_{\mathrm{t}-1}^{16-20}$ & -0.031 & $-0.065^{* *}$ & -0.021 & -0.019 & -0.025 \\
\hline & $\begin{array}{r}\mathrm{R} 2 \\
\end{array}$ & $1.00 \%$ & $1.00 \%$ & $1.10 \%$ & $0.90 \%$ & $0.80 \%$ \\
\hline \multirow[t]{8}{*}{$\mathrm{R}_{\mathrm{t}}^{12-16}$} & Constant & $-0.021^{* *}$ & $-0.025^{* *}$ & -0.01 & -0.001 & $-0.016^{* *}$ \\
\hline & $\mathrm{R}_{\mathrm{t}}^{8-12}$ & -0.008 & 0.013 & -0.028 & 0.038 & 0.008 \\
\hline & $\mathrm{R}_{\mathrm{t}}^{4-8}$ & -0.059 & -0.091 & 0.001 & -0.007 & 0.031 \\
\hline & $\mathrm{R}_{\mathrm{t}}^{0-4}$ & 0.038 & 0.068 & -0.017 & -0.012 & 0.02 \\
\hline & $\mathrm{R}_{\mathrm{t}-1}{ }^{20-24}$ & 0.06 & 0.072 & -0.063 & 0.024 & 0.04 \\
\hline & $\mathrm{R}_{\mathrm{t}-1}{ }^{16-20}$ & 0.017 & 0.049 & -0.047 & -0.038 & $-0.042 *$ \\
\hline & $\mathrm{R}_{\mathrm{t}-1}^{12-16}$ & $-0.100 * *$ & $-0.114 * *$ & $-0.103^{* *}$ & $-0.067 * *$ & $-0.051^{* *}$ \\
\hline & $\mathrm{R} 2$ & $1.10 \%$ & $1.80 \%$ & $1.40 \%$ & $0.70 \%$ & $0.60 \%$ \\
\hline \multirow[t]{8}{*}{$\mathrm{R}_{\mathrm{t}}^{8-12}$} & Constant & $0.030 * *$ & $0.022^{* *}$ & $0.038^{* *}$ & $-0.032 * *$ & -0.003 \\
\hline & $\mathrm{R}_{\mathrm{t}}^{4-8}$ & $-0.080^{* *}$ & -0.067 & $-0.091^{*}$ & -0.039 & -0.036 \\
\hline & $\mathrm{R}_{\mathrm{t}}^{0-4}$ & 0.054 & 0.019 & 0.065 & 0.045 & $0.050^{*}$ \\
\hline & $\mathrm{R}_{\mathrm{t}-1}{ }^{20-24}$ & 0 & -0.01 & -0.041 & 0.047 & 0.056 \\
\hline & $\mathrm{R}_{\mathrm{t}-1}{ }^{16-20}$ & 0.004 & -0.021 & -0.024 & 0.035 & $0.108^{* *}$ \\
\hline & $\mathrm{R}_{\mathrm{t}-1}^{12-16}$ & 0.005 & -0.011 & 0.038 & $0.052 *$ & $0.078^{* *}$ \\
\hline & $\mathrm{R}_{\mathrm{t}-1}^{8-12}$ & $-0.049 * *$ & $-0.134^{* *}$ & 0.004 & -0.003 & 0.005 \\
\hline & $\mathrm{R} 2$ & $0.60 \%$ & $2.10 \%$ & $0.70 \%$ & $0.70 \%$ & $1.90 \%$ \\
\hline \multirow[t]{8}{*}{$\mathrm{R}_{\mathrm{t}}^{4-8}$} & Constant & $0.008^{*}$ & 0.007 & $-0.015^{* *}$ & -0.008 & $\begin{array}{c}-0.009 * \\
\end{array}$ \\
\hline & $\mathrm{R}_{\mathrm{t}}^{0-4}$ & $-0.117 * *$ & $-0.157^{* *}$ & -0.039 & $-0.054^{*}$ & -0.017 \\
\hline & $\mathrm{R}_{\mathrm{t}-1}{ }^{20-24}$ & $-0.071^{* *}$ & $-0.073^{*}$ & -0.035 & $-0.060 *$ & $-0.049 *$ \\
\hline & $\mathrm{R}_{\mathrm{t}-1}{ }^{16-20}$ & $-0.042^{* *}$ & $-0.032 *$ & -0.024 & $-0.056 *$ & 0.003 \\
\hline & $\mathrm{R}_{\mathrm{t}-1}{ }^{12-16}$ & 0.005 & 0.012 & 0.004 & 0.026 & $0.059^{* *}$ \\
\hline & $\mathrm{R}_{\mathrm{t}-1}{ }^{8-12}$ & $0.025^{*}$ & 0.008 & $0.043^{* *}$ & 0.021 & -0.011 \\
\hline & $\mathrm{R}_{\mathrm{t}-1}^{4-8}$ & 0.004 & 0.011 & -0.039 & 0.028 & $-0.057 * *$ \\
\hline & $\mathrm{R} 2$ & $1.50 \%$ & $2.40 \%$ & $0.90 \%$ & $1.10 \%$ & $1.10 \%$ \\
\hline \multirow[t]{8}{*}{$\mathrm{R}_{\mathrm{t}}^{0-4}$} & Constant & -0.005 & 0.002 & -0.005 & 0.012 & $0.012^{*}$ \\
\hline & $\mathrm{R}_{\mathrm{t}-1}{ }^{20-24}$ & $-0.236 * *$ & $-0.198 * *$ & -0.004 & $-0.102 *$ & $-0.165 * *$ \\
\hline & $\mathrm{R}_{\mathrm{t}-1}{ }^{16-20}$ & 0 & -0.004 & 0.013 & 0.019 & $-0.092 * *$ \\
\hline & $\mathrm{R}_{\mathrm{t}-1}^{12-16}$ & 0.006 & $0.030 * *$ & 0 & 0.011 & -0.003 \\
\hline & $\mathrm{R}_{\mathrm{t}-1}^{8-12}$ & $0.034 * *$ & 0.029 & 0.05 & $0.048^{*}$ & $0.034 *$ \\
\hline & $\mathrm{R}_{\mathrm{t}-1}^{4-8}$ & $0.034^{*}$ & 0.032 & $0.035^{* *}$ & $0.076^{*}$ & 0.019 \\
\hline & $\mathrm{R}_{\mathrm{t}-1}^{0-4}$ & -0.024 & -0.034 & $0.016^{*}$ & -0.041 & $-0.053^{* *}$ \\
\hline & $\mathrm{R} 2$ & $5.40 \%$ & $4.00 \%$ & $1.40 \%$ & $1.90 \%$ & $2.70 \%$ \\
\hline
\end{tabular}


Table 6: Cross-sectional returns on bank holidays.

For each currency pair, this table shows the cross-sectional average returns on regular business days and official national holidays. Returns are calculated over two 4-hour periods that constitute representative working hours for the country pairs listed in the second column. The third (fourth) column indicates whether the day in question is an official national holiday for the foreign (domestic) country. Column 5-7 reports the number of observations or days, the annualised mean returns, and two-tail t-statistics for testing the difference in return means between working days and holidays. The last two columns show the standard deviation for the average return and the results of the F-test for evaluating variance equality.

\begin{tabular}{|c|c|c|c|c|c|c|c|c|}
\hline Currency & Working Time & Foreign Festivity & Domestic Festivity & Nbr Obs & Mean & $t$-test & StDev & F-test \\
\hline \multirow{6}{*}{ CHF/USD } & Swiss & No holiday & No holiday & 2931 & $7.2 \%$ & & $5.4 \%$ & \\
\hline & & Swiss holidays & No holiday & 69 & $-4.6 \%$ & 0.01 & $4.1 \%$ & 0.00 \\
\hline & & No holiday & US holidays & 102 & $19.8 \%$ & 0.03 & $4.1 \%$ & 0.00 \\
\hline & US & No holiday & No holiday & 2898 & $-5.2 \%$ & & $6.7 \%$ & \\
\hline & & Swiss holidays & No holiday & 69 & $-21.0 \%$ & 0.05 & $8.1 \%$ & 0.00 \\
\hline & & No holiday & US holidays & 102 & $-7.5 \%$ & 0.41 & $3.8 \%$ & 0.00 \\
\hline \multirow[t]{6}{*}{ DEM/USD } & German & No holiday & No holiday & 1492 & $5.0 \%$ & & $5.0 \%$ & \\
\hline & & German holidays & No holiday & 69 & $-4.6 \%$ & 0.04 & $3.5 \%$ & 0.00 \\
\hline & & No holiday & US holidays & 47 & $16.5 \%$ & 0.06 & $3.5 \%$ & 0.00 \\
\hline & US & No holiday & No holiday & 1492 & $-5.8 \%$ & & $5.7 \%$ & \\
\hline & & German holidays & No holiday & 69 & $-21.1 \%$ & 0.06 & $7.7 \%$ & 0.19 \\
\hline & & No holiday & US holidays & 47 & $-4.6 \%$ & 0.45 & $3.6 \%$ & 0.00 \\
\hline \multirow[t]{6}{*}{ EUR/USD } & EU & No holiday & No holiday & 1677 & $10.3 \%$ & & $4.6 \%$ & \\
\hline & & German holidays & No holiday & 36 & $-3.2 \%$ & 0.03 & $3.9 \%$ & 0.00 \\
\hline & & No holiday & US holidays & 54 & $13.9 \%$ & 0.34 & $3.9 \%$ & 0.00 \\
\hline & US & No holiday & No holiday & 1677 & $-2.3 \%$ & & $6.2 \%$ & \\
\hline & & German holidays & No holiday & 36 & $-4.7 \%$ & 0.16 & $5.6 \%$ & 0.01 \\
\hline & & No holiday & US holidays & 54 & $-1.6 \%$ & 0.21 & $3.2 \%$ & 0.00 \\
\hline \multirow[t]{6}{*}{ JPY/EUR } & Japan & No holiday & No holiday & 1659 & $2.8 \%$ & & $4.6 \%$ & \\
\hline & & Japan holidays & No holiday & 54 & $-16.3 \%$ & 0.01 & $3.9 \%$ & 0.26 \\
\hline & & No holiday & German holidays & 38 & $-0.2 \%$ & 0.01 & $4.1 \%$ & 0.00 \\
\hline & $\mathrm{EU}$ & No holiday & No holiday & 1659 & $-8.0 \%$ & & $6.0 \%$ & \\
\hline & & Japan holidays & No holiday & 54 & $-13.9 \%$ & 0.15 & $5.0 \%$ & 0.26 \\
\hline & & No holiday & German holidays & 38 & $-4.3 \%$ & 0.33 & $3.1 \%$ & 0.00 \\
\hline \multirow[t]{6}{*}{ JPY/USD } & Japan & No holiday & No holiday & 3070 & $2.7 \%$ & & $4.8 \%$ & \\
\hline & & Japan holidays & No holiday & 204 & $0.2 \%$ & 0.28 & $4.5 \%$ & 0.34 \\
\hline & & No holiday & US holidays & 100 & $5.0 \%$ & 0.39 & $5.1 \%$ & 0.00 \\
\hline & US & No holiday & No holiday & 3070 & $-4.0 \%$ & & $5.1 \%$ & \\
\hline & & Japan holidays & No holiday & 204 & $-2.3 \%$ & 0.39 & $4.1 \%$ & 0.01 \\
\hline & & No holiday & US holidays & 100 & $-0.1 \%$ & 0.24 & $4.1 \%$ & 0.00 \\
\hline
\end{tabular}


Figure 1: Intraday Patterns

For each currency pair, these graphs show 24 cross-sectional averages for annualised returns over four hours. T-statistics were used to test (homoscedastic) equality in means. T-statistics refer to two-tail statistics with respect to the difference between a given 4-hour return mean and all the other 4-hour returns. Black (grey) bars mean that an average return over a specific 4-hour time period is different at a $1 \%(5 \%)$ significance level. The time of day is expressed in GMT.

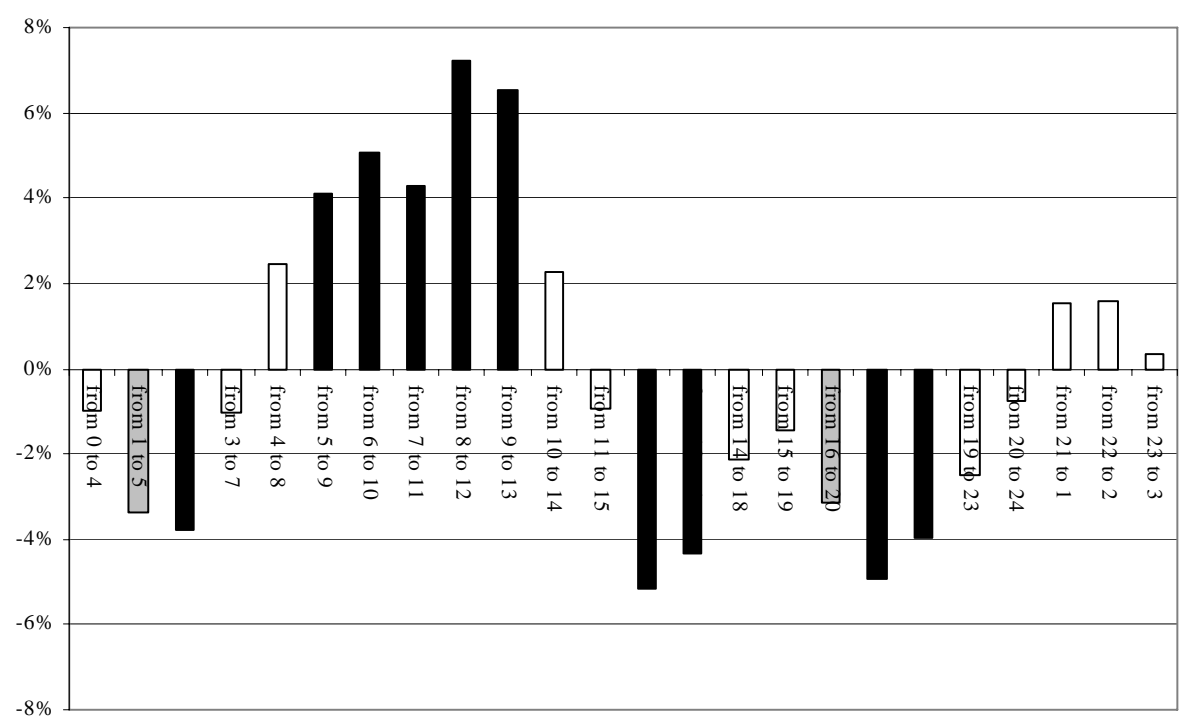

Figure 1A: CHFUSD

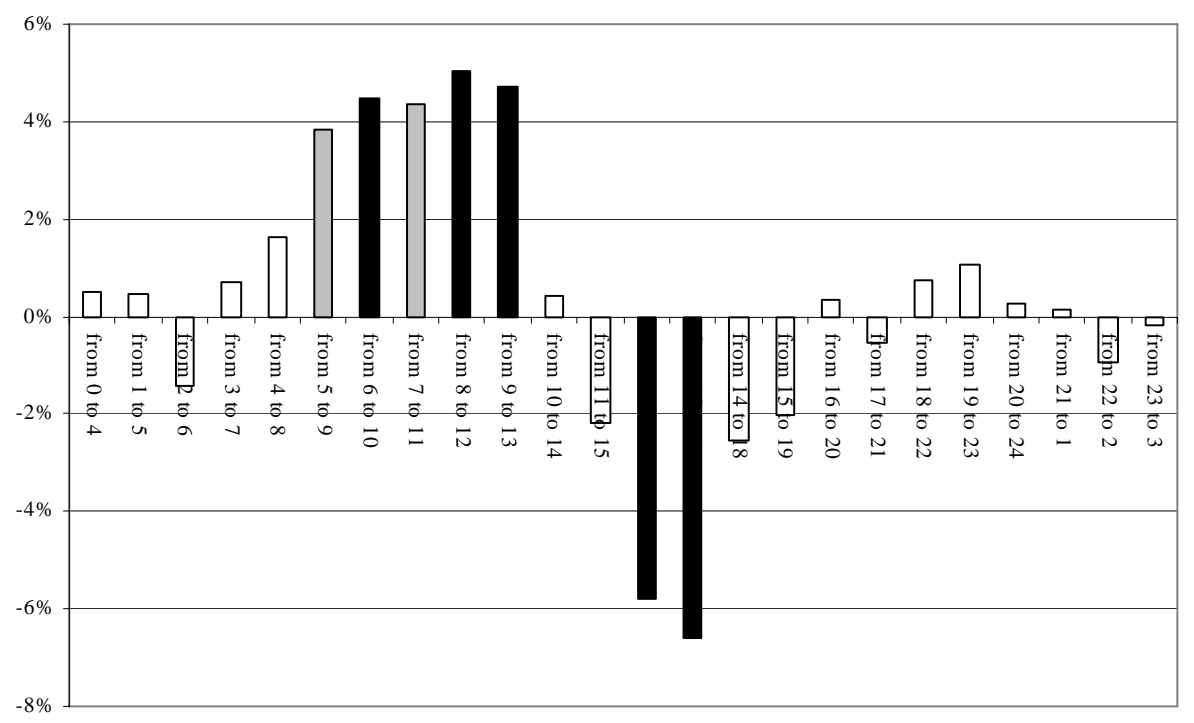

Figure 1B: DEMUSD 


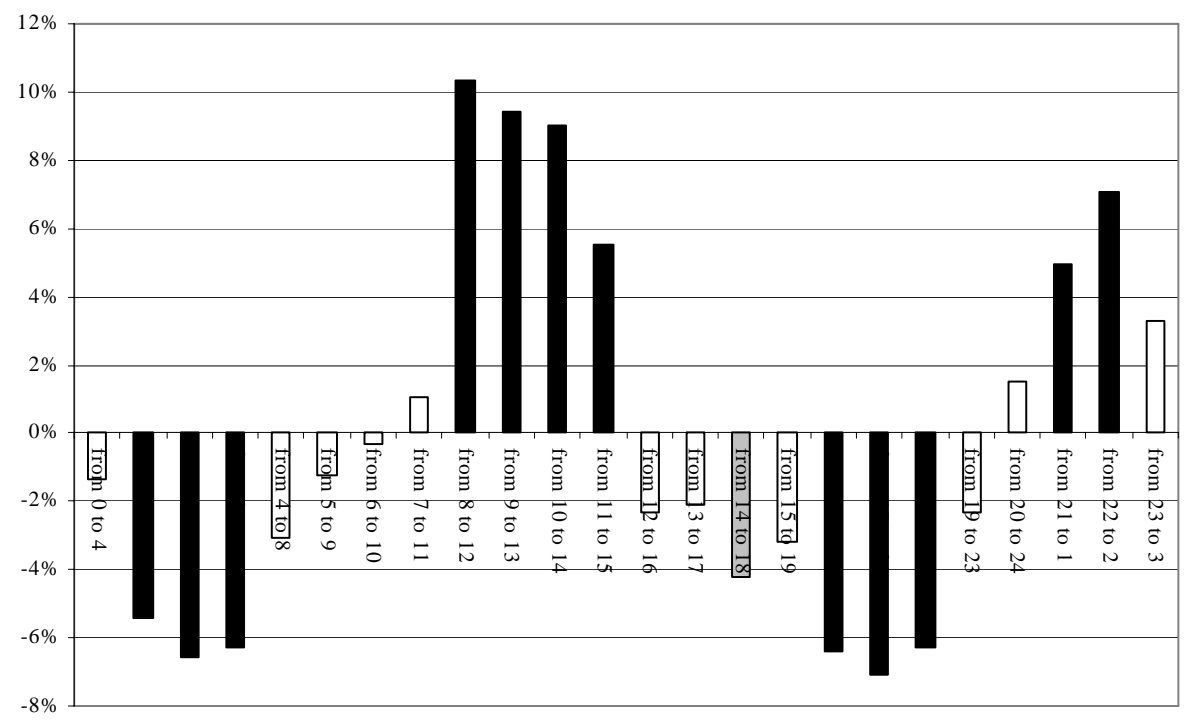

Figure 1C: EURUSD

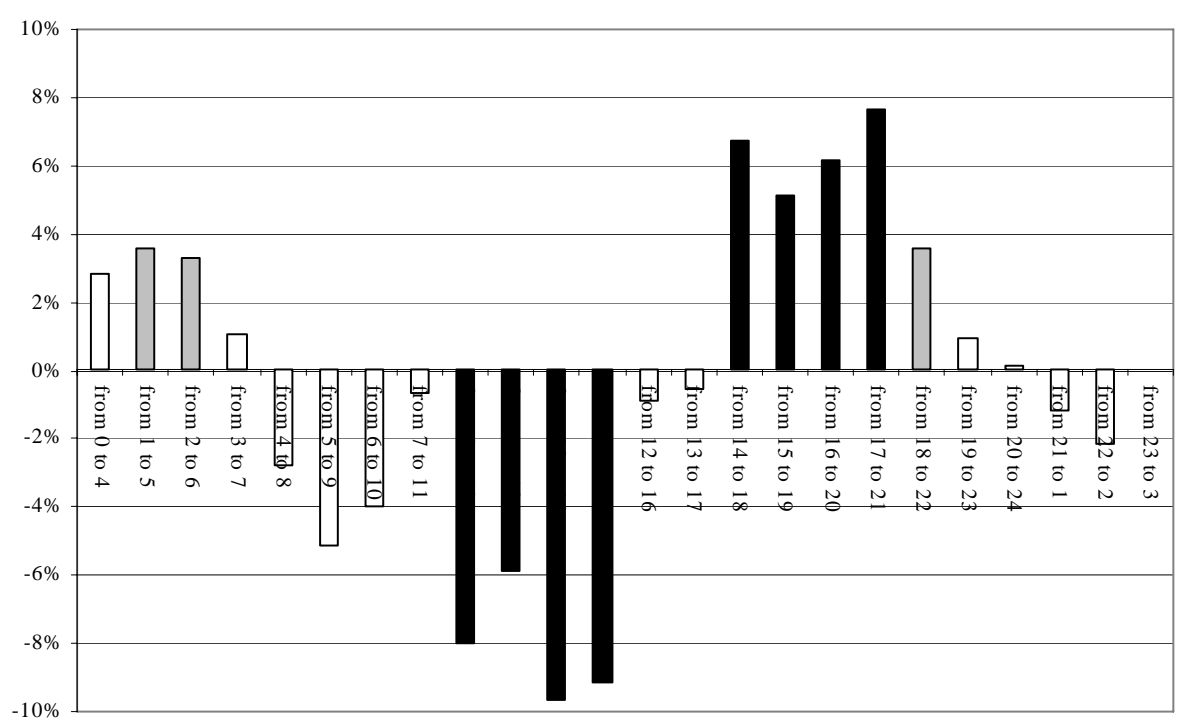

Figure 1D: JPYEUR 


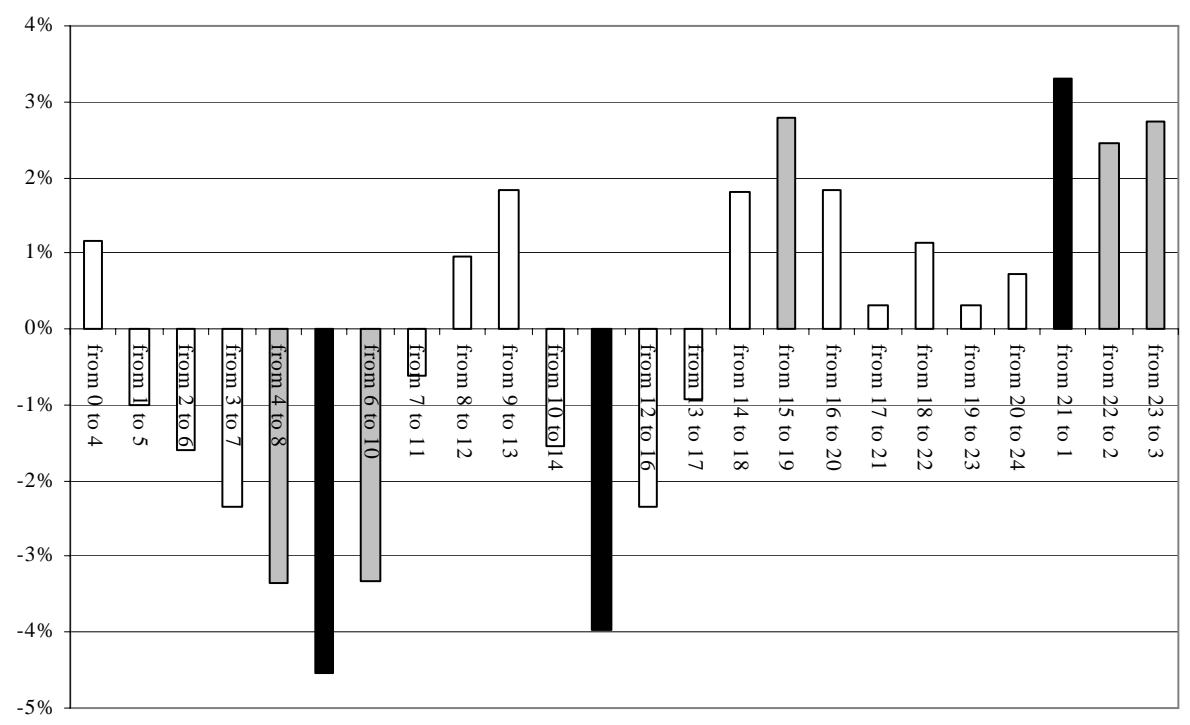

Figure 1E: JPYUSD 
Figure 2: Patterns across years

For each currency pair, these figures show the year-by-year cross-sectional return averages (in annual terms) for a representative 4-hour period in domestic and foreign business hours. Figure $2 \mathrm{~A}$ refers to the appreciation in the domestic currency during foreign working hours. Figure $2 \mathrm{~B}$ refers to the depreciation in the domestic currency during domestic working hours.

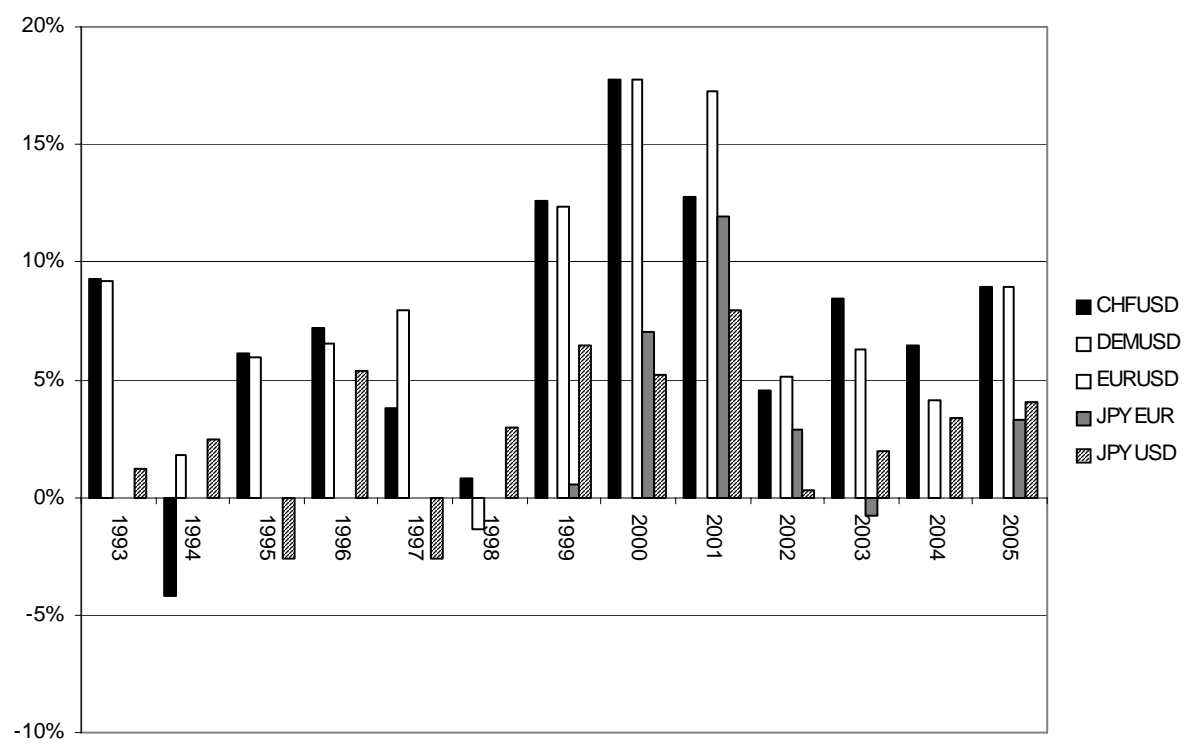

Figure 2A: Domestic currency appreciation during counterpart working time

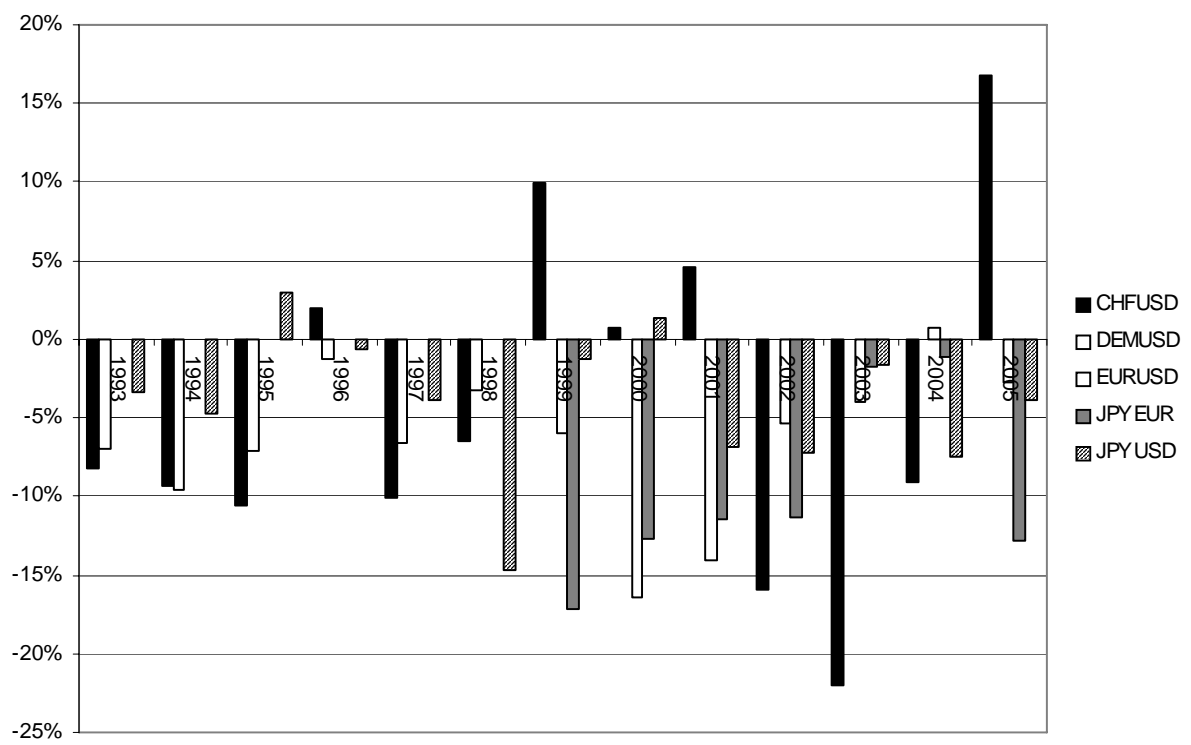

Figure 2B: Domestic currency depreciation during domestic working time 


\section{Swiss National Bank Working Papers published since 2004:}

2004-1 Samuel Reynard: Financial Market Participation and the Apparent Instability of Money Demand

2004-2 Urs W. Birchler and Diana Hancock: What Does the Yield on Subordinated Bank Debt Measure?

2005-1 Hasan Bakhshi, Hashmat Khan and Barbara Rudolf: The Phillips curve under state-dependent pricing

2005-2 Andreas M. Fischer: On the Inadequacy of Newswire Reports for Empirical Research on Foreign Exchange Interventions

2006-1 Andreas M. Fischer: Measuring Income Elasticity for Swiss Money Demand: What do the Cantons say about Financial Innovation?

2006-2 Charlotte Christiansen and Angelo Ranaldo: Realized Bond-Stock Correlation: Macroeconomic Announcement Effects

2006-3 Martin Brown and Christian Zehnder: Credit Reporting, Relationship Banking, and Loan Repayment

2006-4 Hansjörg Lehmann and Michael Manz: The Exposure of Swiss Banks to Macroeconomic Shocks - an Empirical Investigation

2006-5 Katrin Assenmacher-Wesche and Stefan Gerlach: Money Growth, Output Gaps and Inflation at Low and High Frequency: Spectral Estimates for Switzerland

2006-6 Marlene Amstad and Andreas M. Fischer: Time-Varying Pass-Through from Import Prices to Consumer Prices: Evidence from an Event Study with Real-Time Data

2006-7 Samuel Reynard: Money and the Great Disinflation

2006-8 Urs W. Birchler and Matteo Facchinetti: Can bank supervisors rely on market data? A critical assessment from a Swiss perspective

2006-9 Petra Gerlach-Kristen: A Two-Pillar Phillips Curve for Switzerland

2006-10 Kevin J. Fox and Mathias Zurlinden: On Understanding Sources of Growth and Output Gaps for Switzerland

2006-11 Angelo Ranaldo: Intraday Market Dynamics Around Public Information Arrivals

2007-1 Andreas M. Fischer, Gulzina Isakova and Ulan Termechikov: Do FX traders in Bishkek have similar perceptions to their London colleagues? Survey evidence of market practitioners' views 
2007-2 Ibrahim Chowdhury and Andreas Schabert: Federal Reserve Policy viewed through a Money Supply Lens

2007-3 Angelo Ranaldo: Segmentation and Time-of-Day Patterns in Foreign Exchange Markets 
Swiss National Bank Working Papers are also available at www.snb.ch, section Publications/Research Subscriptions or individual issues can be ordered at Swiss National Bank, Fraumünsterstrasse 8, CH-8022 Zurich, fax+41 4463181 14, E-mail library@snb.ch 